\title{
A search for the $\mathrm{OH} 6035 \mathrm{MHz}$ line in high-mass star-forming regions
}

\author{
M. Szymczak ${ }^{1}$, P. Wolak ${ }^{1}$, A. Bartkiewicz ${ }^{1}$, M. Aramowicz ${ }^{2}$, and M. Durjasz ${ }^{1}$ \\ ${ }^{1}$ Institute of Astronomy, Faculty of Physics, Astronomy and Informatics, Nicolaus Copernicus University, Grudziadzka 5, 87-100 \\ Torun, Poland \\ e-mail: msz@astro.umk.pl \\ 2 Astronomical Institute, University of Wrocław, ul. Kopernika 11, 51-622 Wrocław, Poland
}

Received 23 July 2020 / Accepted 2 September 2020

\begin{abstract}
Context. The excited states of $\mathrm{OH}$ masers detected in the environment of high-mass young stellar objects (HMYSOs) are important for improving our understanding of the physical conditions of these objects and also provide information about their magnetic fields. Aims. We aim to search for excited-state $\mathrm{OH} 6035 \mathrm{MHz}$ maser emission in HMYSOs which might have escaped detection in previous surveys or were never searched for.

Methods. A sample of HMYSOs derived from untargeted surveys of the $6668 \mathrm{MHz}$ methanol maser line was observed at $6035 \mathrm{MHz}$ $\mathrm{OH}$ transition with the Torun $32 \mathrm{~m}$ radio telescope. The $6035 \mathrm{MHz}$ detections were observed in the $\mathrm{OH} 6031 \mathrm{MHz}$ line. Two-thirds of the detections were observed at least three times over a two-year period.

Results. Out of 445 targets, 37 were detected at $6035 \mathrm{MHz}$, including seven new discoveries. The $6031 \mathrm{MHz}$ line was detected towards ten $6035 \mathrm{MHz}$ sources, one of which was not previously reported. All the newly detected sources are faint with the peak flux density lower than $4 \mathrm{Jy}$ and show significant or high variability on timescales of 4 to 20 months. Zeeman pair candidates identified in three new sources imply a magnetic field intensity of $2-11 \mathrm{mG}$. Comparison of our spectra with those obtained $\sim 10 \mathrm{yr}$ ago indicates different degrees of variability but there is a general increase in the variability index on an $\sim 25 \mathrm{yr}$ timescale, usually accompanied by significant changes in the profile shape.
\end{abstract}

Key words. masers - stars: massive - stars: formation - ISM: molecules - radio lines: ISM

\section{Introduction}

Observations of spectral lines in the gas surrounding high-mass young stellar objects (HMYSOs) are one of the important tools to determine the physical and chemical conditions which enable the examination of mechanisms and star formation processes (Zinnecker \& Yorke 2007). Maser lines are of special interest in this context as useful signposts of star formation activity (e.g. Menten 1991; Caswell 2003; Breen et al. 2015) which owing to their high levels of brightness and compactness can probe neutral gas cloudlets of a few tens of astronomical units (au) in size that reside in rotating structures such as toroids and discs (Beltrán \& de Wit 2016) or around powerful jets (e.g. Anglada et al. 2018).

Ground-state $\mathrm{OH}$ maser transitions are one of the essential signatures of HMYSOs in their early stages of formation and have been detected in numerous sites (e.g. Caswell 1999; Forster \& Caswell 1999; Argon et al. 2000; Edris et al. 2007; Beuther et al. 2019; Qiao et al. 2020). They are sometimes accompanied by the excited-state $\mathrm{OH}\left({ }^{2} \Pi_{3 / 2}, J=5 / 2\right)$ transitions at $5 \mathrm{~cm}$ wavelength, where the main line $6035 \mathrm{MHz}$ dominates in most cases (Yen et al. 1969; Knowles et al. 1976; Smits 1994; Caswell \& Vaile 1995; Baudry et al. 1997; Caswell 2001, 2003; Avison et al. 2016). As this excited state of $\mathrm{OH}$ lies immediately above the ground state, it provides a critial test for maser pumping schemes (Baudry et al. 1997; Pavlakis \& Kylafis 2000; Cragg et al. 2002). OH is a paramagnetic molecule, and therefore a significant Zeeman splitting is observed for the transitions, allowing reliable estimates of the magnetic field strength and its direction (Baudry et al. 1997; Caswell \& Vaile 1995; Caswell 2003).
Most of past surveys of the excited-state $\mathrm{OH}$ maser transitions were commonly restricted to targets identified by groundstate OH masers (Caswell \& Vaile 1995; Baudry et al. 1997) and obviously suffer from biases. Detection of the $6.7 \mathrm{GHz}$ methanol line (Menten 1991), which is uniquely associated with star forming regions, opened a new path to identify more HMYSOs. Indeed, recent surveys of the $6.7 \mathrm{GHz}$ line resulted in detection of several previously unknown HMYSOs, enlarging the number of candidates in early stages, where the massive star is still in an active phase of accretion and is deeply embedded in the parent molecular clouds (e.g. Green et al. 2010; Szymczak et al. 2012; Breen et al. 2015). Recently, the first complete untargeted survey of the accessible southern Galactic plane for the $\mathrm{OH} 6035 \mathrm{MHz}$ line was carried out as part of the Methanol Multibeam Survey (MMB, Avison et al. 2016, 2020). In this paper we report the results of the $\mathrm{OH} 6035 \mathrm{MHz}$ survey of HMYSO candidates with which we aim to expand the sample of excited-state $\mathrm{OH}$ sources, particularly for the northern hemisphere, and to search for sources that may have escaped detection in previous observations due to variability. Observations of excited-state $\mathrm{OH}$ masers may allow us to find targets for multi-line maser studies with high angular resolution.

\section{Observations}

Observations of the ${ }^{2} \Pi_{3 / 2}, J=5 / 2, F=3-3 \mathrm{OH}$ transition at $6035.092 \mathrm{MHz}$ were carried out from June to September 2018 with the Torun $32 \mathrm{~m}$ radio telescope. Detections were reobserved in two sessions: November-December 2018 and 
Table 1. $6035 \mathrm{GHz} \mathrm{OH}$ line parameters for the new detections.

\begin{tabular}{|c|c|c|c|c|c|c|c|c|c|}
\hline \multirow[b]{2}{*}{ Name (l b) } & \multirow[b]{2}{*}{ RA (J2000) } & \multirow[b]{2}{*}{$\begin{array}{c}\operatorname{Dec}(\mathrm{J} 2000) \\
\left({ }^{\circ},{ }^{\prime},\right)\end{array}$} & \multirow[b]{2}{*}{$\begin{array}{c}\Delta V \\
\left(\mathrm{~km} \mathrm{~s}^{-1}\right)\end{array}$} & \multicolumn{3}{|c|}{ LHC } & \multicolumn{3}{|c|}{ RHC } \\
\hline & & & & $\begin{array}{c}V_{\mathrm{p}} \\
\left(\mathrm{km} \mathrm{s}^{-1}\right)\end{array}$ & $\begin{array}{c}S_{\mathrm{p}} \\
(\mathrm{Jy}) \\
\end{array}$ & $\begin{array}{c}S_{\mathrm{i}} \\
\left(\mathrm{Jy} \mathrm{km} \mathrm{s}^{-1}\right) \\
\end{array}$ & $\begin{array}{c}V_{\mathrm{p}} \\
\left(\mathrm{km} \mathrm{s}^{-1}\right)\end{array}$ & $\begin{array}{l}S_{\mathrm{p}} \\
(\mathrm{Jy})\end{array}$ & $\begin{array}{c}S_{\mathrm{i}} \\
\left(\mathrm{Jy} \mathrm{km} \mathrm{s}^{-1}\right) \\
\end{array}$ \\
\hline G12.209-00.102 & 181239.92 & -182417.9 & $16.0 ; 18.2$ & 16.97 & 1.78 & 1.41 & 17.35 & 2.47 & 1.14 \\
\hline G25.710+00.044 & 183803.15 & -062414.9 & $93.6 ; 96.0$ & 95.52 & 1.12 & 0.93 & 95.45 & 0.85 & 0.90 \\
\hline G28.146-00.005 & 184242.59 & -041536.5 & $101.0 ; 101.6$ & 101.38 & 1.27 & 0.35 & 101.42 & 2.89 & 0.73 \\
\hline G85.410+00.003 & 205413.68 & +445407.6 & $-33.3 ;-32.7$ & -32.92 & 0.74 & 0.30 & -32.97 & 2.00 & 0.61 \\
\hline G90.921+01.486 & 210912.98 & +500103.6 & $-70.5 ;-68.4$ & -69.24 & 1.00 & 0.66 & -69.20 & 1.89 & 0.81 \\
\hline G108.766-00.986 & 225851.18 & +584514.4 & $-46.3 ;-44.7$ & -45.37 & 0.95 & 0.49 & -45.95 & 2.21 & 1.21 \\
\hline G183.348-00.575 & 055110.94 & +254617.2 & $-6.1 ;-5.0$ & -5.30 & 3.68 & 1.13 & -5.29 & 0.78 & 0.20 \\
\hline G183.348-00.575 $(a)$ & 055110.94 & +254617.2 & $-5.4 ;-4.9$ & -5.15 & 1.27 & 0.27 & & $<0.61^{(b)}$ & $<0.05$ \\
\hline
\end{tabular}

Notes. The velocity range of $I$ Stokes emission $(\Delta V)$, the peak velocity $\left(V_{\mathrm{p}}\right)$, peak flux density $\left(S_{\mathrm{p}}\right)$, and integrated flux density $\left(S_{\mathrm{i}}\right)$ for the LHC and RHC polarisation are given. ${ }^{(a)} 6031 \mathrm{MHz}$ transition, ${ }^{(b)} 3 \sigma$ level.
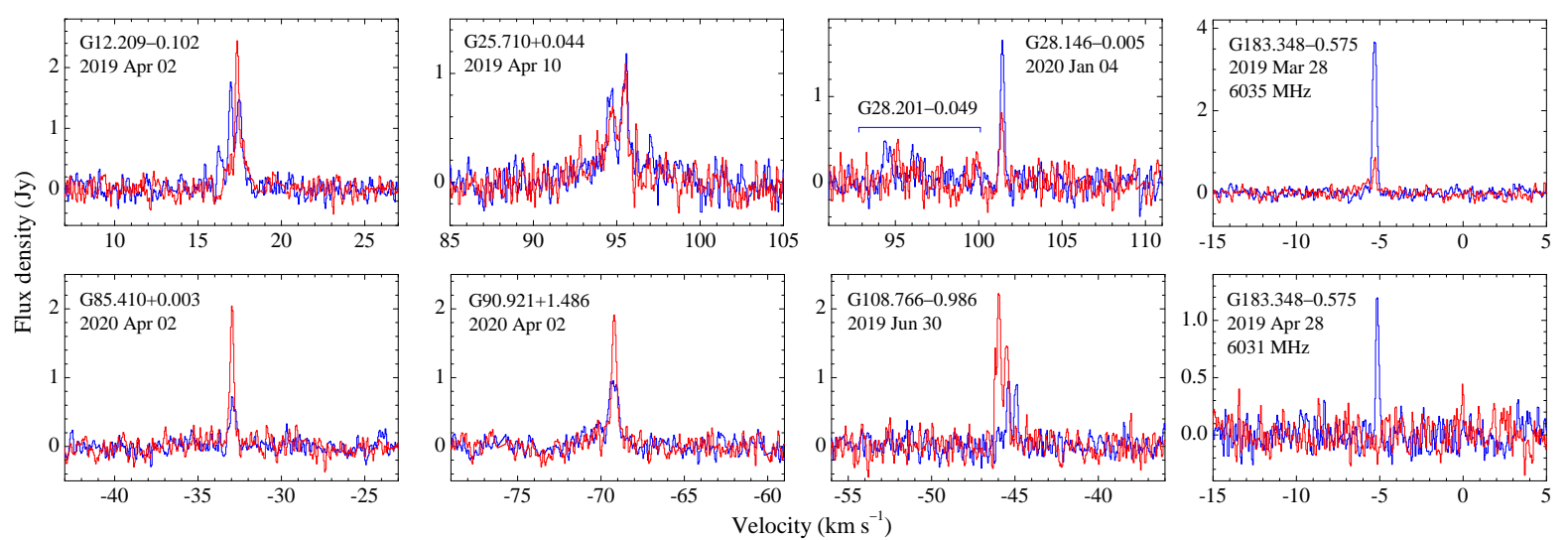

Fig. 1. $6035 \mathrm{MHz} \mathrm{OH}$ maser spectra of newly detected sources from the Torun observations. The new detection of the $6031 \mathrm{MHz}$ transition for one target is also shown. Blue and red lines denote LHC and RHC polarisation, respectively. Observation dates are given.

March-April 2019, and since then several sources have been monitored. Furthermore, all of them were also searched for the ${ }^{2} \Pi_{3 / 2}, J=5 / 2, F=2-2$ line at $6030.747 \mathrm{MHz}$. The telescope has a half-power beam width of 6.4 at these frequencies and the pointing accuracy was about $10^{\prime \prime}$. The observations were pointed on the positions of $6668 \mathrm{MHz}$ methanol maser sources whose coordinates are known with sub-arcsecond accuracy in almost all cases. The sample includes all the methanol masers from the Torun catalogue (Szymczak et al. 2012) updated with objects above declination $-22^{\circ}$ from the Multibeam Methanol Survey (Green et al. 2010; Breen et al. 2015). The targets were observed in left- and right-hand circular (LHC and RHC) polarisation simultaneously using a dual-channel receiver system with the system temperature ranging from 25 to $30 \mathrm{~K}$. The IEEE convention for the handedness of polarisation was adopted and Stokes $V$ parameter was defined following the IAU convention as $V=S$ (RHC) $-S$ (LHC), where $S$ (RHC) and $S$ (LHC) are the line flux densities for right and left circular polarisation, respectively. Spectra were obtained with an autocorrelation spectrometer in the frequency-switching mode using two banks of 4096 channels each, covering a velocity range of $95 \mathrm{~km} \mathrm{~s}^{-1}$ with a velocity resolution of $0.1 \mathrm{~km} \mathrm{~s}^{-1}$ after Hanning smoothing. The spectra were centred at the middle velocity of the methanol maser profiles measured relative the local standard of rest. Typical integration lasted 20 min resulting in an rms noise level of $0.20-0.25 \mathrm{Jy}$ for a single polarisation flux density. Parameters of the receiving system were regularly measured through observations of continuum and spectral line calibrators as described in Szymczak et al. (2012). The gain of each polarisation channel was measured with a noise diode at the beginning of each ninety-second integration cycle to $\sim 10 \%$ in absolute value and to within $\sim 4 \%$ in relative value. The degree of circular polarisation is defined as $m_{\mathrm{C}}=V / I$, where $V$ and $I$ are Stokes parameters of circularly polarised emission and total emission, respectively.

\section{Results}

Among 445 targets observed, the $6035 \mathrm{MHz}$ emission was detected in 37 objects of which 7 are new detections. The $6031 \mathrm{MHz}$ emission was detected towards ten $6035 \mathrm{MHz}$ objects. The parameters of spectra of new and known sources ordered by galactic longitude are listed in Tables 1 and A.1, respectively. The spectra of new detections are shown in Fig. 1 and those of known sources are in Fig. A.1. A list of non-detections is provided in Table A.2.

The following notes provide information on a possible association of the $6035 \mathrm{MHz}$ emission with the $6668 \mathrm{MHz}$ masers on the basis of velocities of their maser peaks and systemic velocity of the parent molecular clouds. Estimates of the magnetic field strength of some of the masers and comments on the degree of circular polarisation are also given.

G12.209-00.102. The $6035 \mathrm{MHz}$ maser emission detected in a velocity range of $16-18.5 \mathrm{~km} \mathrm{~s}^{-1}$, with $\left|m_{\mathrm{C}}\right| \approx 30-40 \%$ for the strongest features, is $\sim 5 \mathrm{~km} \mathrm{~s}^{-1}$ blueshifted from $\mathrm{OH}$ $1665 \mathrm{MHz}$ maser features (Argon et al. 2000) but coincides 
well with the $6668 \mathrm{MHz}$ methanol emission range (Green et al. 2010). The $1665 \mathrm{MHz}$ emission lies within less than $2^{\prime \prime}$ from the methanol maser (Argon et al. 2000; Caswell 2009) and at this position there are five methanol masers (Caswell 2009; Green et al. 2010) in the telescope beam. The $6035 \mathrm{MHz}$ spectrum shows strong variability (Sect. 4.4) preserving possible Zeeman splitting which corresponds to a magnetic field of +2.6 to $+8.8 \mathrm{mG}$ (Table A.3).

G25.709+00.044. The $6035 \mathrm{MHz}$ maser shows weakly polarised emission with double peaks around $95 \mathrm{~km} \mathrm{~s}^{-1}$. Avison et al. $(2016,2020)$ reported an almost identical $6035 \mathrm{MHz}$ spectrum towards G25.509-0.060 which these latter authors referred to as an isolated excited-state $\mathrm{OH}$ source because it has no $6668 \mathrm{MHz}$ methanol maser within $>6.5$, or $22 \mu \mathrm{m}$ WISE counterpart within 1.2 , or $1.1 \mathrm{~mm}$ ATLASGAL emission within $2^{\prime}$. At this position we did not find $6035 \mathrm{MHz}$ emission with upper limit of $0.5 \mathrm{Jy}$ in 2020 April while the intensity towards $\mathrm{G} 25.710+0.044$ was $0.9 \mathrm{Jy}(>4 \sigma)$ at the same epoch confirming this as a new detection.

G28.146-00.005. The $6035 \mathrm{MHz}$ spectrum contains a narrow feature at $101.4 \mathrm{~km} \mathrm{~s}^{-1}$ which is significantly polarised $\left(m_{\mathrm{C}}=40 \%\right)$ and exactly coincides in velocity with the strongest feature of the $6668 \mathrm{MHz}$ maser (Breen et al. 2015). In our spectrum, a side-lobe emission from G28.201-0.049 is seen at a velocity lower than $96.5 \mathrm{~km} \mathrm{~s}^{-1}$ (Caswell \& Vaile 1995; Baudry et al. 1997).

G85.410+0.003. The $6035 \mathrm{MHz}$ spectrum is markedly polarised $\left(m_{\mathrm{C}}=54 \%\right)$ and the peak velocity lies at the lowvelocity edge of the $\mathrm{CH}_{3} \mathrm{OH}$ and $\mathrm{H}_{2} \mathrm{O}$ maser spectra (Szymczak et al. 2012; Urquhart et al. 2011) very close to the systemic velocity of $-35.8 \mathrm{~km} \mathrm{~s}^{-1}$ derived from $\mathrm{NH}_{3}$ lines (Urquhart et al. 2011). This new source is associated with an embedded stellar cluster of very young stars (Persi et al. 2011) where the $6668 \mathrm{MHz}$ maser coincides within 0.3 with a compact HII region detected at centimetre wavelengths (Urquhart et al. 2009; Hu et al. 2016).

G90.921+1.486. This source has $6035 \mathrm{MHz}$ polarised emission $\left(m_{\mathrm{C}}=38 \%\right)$ at the same velocity as the most redshifted feature, $-69.2 \mathrm{~km} \mathrm{~s}^{-1}$, of the $6668 \mathrm{MHz}$ methanol maser (Szymczak et al. 2012). A tentative absorption feature centred at $-73.5 \mathrm{~km} \mathrm{~s}^{-1}$ is seen. A weak feature of the $\mathrm{OH} 1667 \mathrm{MHz}$ (Szymczak \& Kus 2000) was blueshifted by $3.3 \mathrm{~km} \mathrm{~s}^{-1}$ from the $6035 \mathrm{MHz}$ feature. The methanol maser is associated with a compact HII region (Hu et al. 2016).

G108.766-00.986. Double components of $6035 \mathrm{MHz}$ maser emission are seen at the exact velocity of the strongest $6668 \mathrm{MHz}$ maser feature at $-46.6 \mathrm{~km} \mathrm{~s}^{-1}$ (Szymczak et al. 2012). These are blueshifted by $6 \mathrm{~km} \mathrm{~s}^{-1}$ from the systemic velocity and $\mathrm{H}_{2} \mathrm{O}$ maser velocity range (Urquhart et al. 2011). There is a consistent Zeeman pair seen for the whole emission implying a magnetic field of $-10 \mathrm{mG}$.

G183.348-00.575. A highly polarised feature $\left(m_{\mathrm{C}}=\right.$ $-65 \%)$ is detected at a velocity of $-5.3 \mathrm{~km} \mathrm{~s}^{-1}$. The strongest $6668 \mathrm{MHz}$ methanol feature is seen at nearly the same velocity (Szymczak et al. 2012). The $\mathrm{OH} 6035 \mathrm{MHz}$ emission is redshifted by $4.3 \mathrm{~km} \mathrm{~s}^{-1}$ from the systemic velocity (Wu et al. 2010). Newly detected $6031 \mathrm{MHz}$ emission closely matches the main $6035 \mathrm{MHz}$ feature; it is completely polarised and has the narrowest profile with a width to half intensity of only $0.21 \mathrm{~km} \mathrm{~s}^{-1}$.

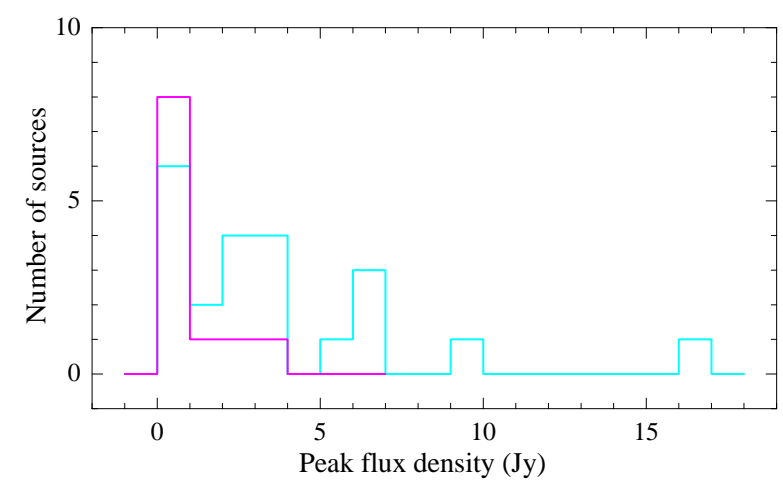

Fig. 2. $\mathrm{OH} 6035 \mathrm{MHz}$ peak flux of sources in the Galactic longitude range $8^{\circ}$ to $60^{\circ}$ from the Avison et al. (2016) MMB survey. The $\mathrm{OH}$ sources coincide with $6.7 \mathrm{GHz}$ methanol masers within $10^{\prime \prime}$. The histograms show $\mathrm{OH}$ detection (cyan) and non-detection (magenta) in the present survey.

\section{Discussion}

\subsection{Detection rate and methanol/hydroxyl luminosity ratio}

In the Galactic longitude of $8-60^{\circ}$, our survey overlaps with the MMB untargeted observations and there are 375 methanol masers at $6.7 \mathrm{GHz}$ (Green et al. 2010; Breen et al. 2015) of which $33(8.8 \%)$ have an $\mathrm{OH} 6035 \mathrm{MHz}$ maser counterpart within $<10^{\prime \prime}$ (Avison et al. 2016). There are also ten $\mathrm{OH}$ sources without a methanol counterpart within $10^{\prime \prime}$. In the present observation of this area the number of $\mathrm{OH}$ sources associated (within 10") with the methanol maser decreased to $22(5.9 \%)$. The three new $\mathrm{OH}$ sources are not taken into account because with the beam of 6'.4 we were not able to discern whether or not they meet the above criterion of coincidence with the methanol masers. As a consequence of slightly lower sensitivity (by $\sim 25 \%$ ), our detection rate is lower than that inferred from the MMB survey. Similar to previous studies (Avison et al. 2016, 2020), we find that the $\mathrm{OH} 6035 \mathrm{MHz}$ maser emission is rather sparsely associated with the sources of the $6.7 \mathrm{GHz}$ maser line. This implies that coexistence of $6.7 \mathrm{GHz}$ methanol and $6035 \mathrm{MHz}$ hydroxyl masers traces rather uncommon physical conditions with a narrow range of gas density of about $10^{8} \mathrm{~cm}^{-3}$ and low kinetic temperature of $<50 \mathrm{~K}$ (Cragg et al. 2002). High-angular-resolution studies are required in order to decipher whether or not these transitions come from the same gas volume.

Figure 2 shows the distribution of peak flux density of $33 \mathrm{OH}$ masers at epochs (2008-2009) of MMB observations (Avison et al. 2016) in the overlapped area. The six $\mathrm{OH}$ sources found by these latter authors with peak flux density above our sensitivity limit of $0.7 \mathrm{Jy}$ are not detected, while their $5 \mathrm{OH}$ sources below this threshold are seen in the present survey. This implies considerable variability of $6035 \mathrm{MHz}$ transition on a timescale of $\sim 10 \mathrm{yr}$; this point is further discussed in Sect. 4.4.

In the $8-60^{\circ}$ region we found four $\mathrm{OH}$ masers which coincide within less than 0.5 with the $6.7 \mathrm{GHz}$ sources and show distinct emission at the same velocities. Using the methanol unpublished spectra taken with the Torun $32 \mathrm{~m}$ telescope (Szymczak et al. 2018) at almost the same epochs ( \pm 3 days), we calculated the ratio of $6.7 \mathrm{GHz}$ to $6.035 \mathrm{MHz}$ isotropic luminosity for the $\mathrm{OH}$ velocity range. For two features of G15.034-00.677 centred at 21.4 and $23.5 \mathrm{~km} \mathrm{~s}^{-1}$ this ratio is 1.9 and 2.6 , respectively, while for the strongest $\mathrm{OH}$ features of $\mathrm{G} 20.237+00.065$ and G35.025+00.350 it is 2.5 and 3.1, respectively, and in 
G11.904-00.141 the ratio is 30.5. It is surprising that in the three objects, the luminosity of the $6.7 \mathrm{GHz}$ line is only a factor of two to three higher than that of the $6.035 \mathrm{MHz}$ line. This may suggest very specific conditions, for instance where the methanol maser is quenched due to collisions in high-density gas while the $\mathrm{OH} 6.035 \mathrm{MHz}$ maser is still excited (Cragg et al. 2002). We stress that our estimates need to be verified with highangular-resolution observations to confirm whether or not both transitions are really co-spacial.

\subsection{Line width}

For all spectral features with a signal-to-noise ratio $(\mathrm{S} / \mathrm{N})$ greater than five we fitted Gaussian components to estimate the line parameters. We identify 61 LHC and 66 RHC spectral features of previously known sources and 11 features at both polarisations of new detections at the $6035 \mathrm{MHz}$ transition. We also find $10 \mathrm{LHC}$ and $11 \mathrm{RHC}$ components at the $6031 \mathrm{MHz}$ transition for known sources and one LHC component for the new detection. The full width at half maximum (FWHM) at $6035 \mathrm{MHz}$ ranges from 0.16 to $0.95 \mathrm{~km} \mathrm{~s}^{-1}$ and the mean and median values are $0.41 \pm 0.05$ and $0.36 \mathrm{~km} \mathrm{~s}^{-1}$, respectively. These values are larger by a factor of 1.8 than those inferred from high-angularresolution data (Desmurs et al. 1998; Fish \& Sjouwerman 2007). This discrepancy is likely due to spatial filtering out of the emission in VLBI observations where the brightest, most compact maser cloudlets are seen and the line width is lower as compared to single dish spectra. Another possibility is that Gaussian fitting failed for blended spectra obtained with our moderate sensitivity. The mean and median values of FWHM at $6031 \mathrm{MHz}$ are $0.33 \pm 0.06$ and $0.36 \mathrm{~km} \mathrm{~s}^{-1}$ and are consistent with those for the $6035 \mathrm{MHz}$ transition. This supports the conclusions of previous studies (e.g. Baudry et al. 1997; Fish \& Sjouwerman 2007). For the new detection of $6031 \mathrm{MHz}$ emission, the FWHM of the isolated component is $0.21 \mathrm{~km} \mathrm{~s}^{-1}$. We did not find any correlation between line width and flux density.

\subsection{Zeeman pair candidates}

We used the convention that a field directed away from the observer has a positive sign and is indicated by the RHC component at more positive velocity that the LHC component. The following coefficients were used for the magnetic field strength estimation derived from the velocity separation of each pair: $\Delta V\left(\mathrm{~km} \mathrm{~s}^{-1}\right) / \mathrm{H}(\mathrm{mG})=0.056$ and 0.079 at $6035 \mathrm{MHz}$ and $6031 \mathrm{MHz}$, respectively (Baudry et al. 1997).

Zeeman pairs were categorised based on a comparison of the Gaussian fits of the spectral components (Sect. 4.2). The fitted peak velocities and FWHM values but no peak amplitudes were used for comparison. For complex spectra, only the prominent spectral components were considered to match pairs of components with nearby velocities and opposite senses of polarisation. We neglected pairs with one component lying on the edge of the other component.

We identified $34 \mathrm{LHC} / \mathrm{RHC}$ pairs at the $6035 \mathrm{MHz}$ and 9 pairs at the $6031 \mathrm{MHz}$ transition; see Table A.3, where we also list the fitted peak velocities and flux densities, demagnetized velocities, field strength, reliability of Zeeman pair identification, and field strength from the literature. The inferred magnetic field ranges from 0.1 to $12.0 \mathrm{mG}$ as indicated by the splitting of the $6035 \mathrm{MHz}$ line and from 0.2 to $9.0 \mathrm{mG}$ of the $6031 \mathrm{MHz}$ line. The mean and median values are 4.6 and $4.4 \mathrm{mG}(6035 \mathrm{MHz})$, and 4.6 and $3.9 \mathrm{mG}(6031 \mathrm{MHz})$.

The possible Zeeman pairs listed in Table A.3 should be treated with care, especially those labelled "B". All the pairs need to be verified with high-angular-resolution observations to definitively demonstrate that the candidate Zeeman pairs spatially coincide and are thus genuinely associated. Nevertheless, our estimates of the magnetic field seem to be consistent with those reported in the literature (Table A.3); in most cases, we obtained similar field strength and in all cases the same field direction.

Caswell (1997) pointed out that there was no field greater than about $10 \mathrm{mG}$. Therefore, it will be important to verify, using interferometric data, the magnetic field strengths in G12.68100.182, G69.540-00.976, and G108.7666-00.986, where our estimated values exceeded $10 \mathrm{mG}$. Moreover, in G15.03500.677 , G45.467+00.053, and G80.861+00.383 the field reversal is seen and follow-up studies would be desirable to uncover the magnetic field morphology.

Three objects (G11.034+00.062, G11.904-00.141 and G15.035-00.677) were observed in full polarisation by Green et al. (2015). For the first two sources, our estimates of the magnetic field strength are only roughly $(35 \%)$ consistent with the values of these latter authors (Table A.3). This could be due to the fact that our spectra are much noisier than theirs. In the case of the bright source G15.035-00.677 whose $6031 \mathrm{MHz}$ profile was identified as a Zeeman triplet candidate (Green et al. 2015), we obtained field strengths similar to those reported in the literature (Table A.3).

\subsection{Variability}

Most of our newly detected sources were observed three or more times over a period of less than two years. To quantify their variability we used the variability index given by

$v i=\frac{\left(S_{\max }-\sigma_{\max }\right)-\left(S_{\min }+\sigma_{\min }\right)}{\left(S_{\max }-\sigma_{\max }\right)+\left(S_{\min }+\sigma_{\min }\right)}$

which is a measure of the amplitude of the variability of the spectral feature. Here, $S_{\max }$ and $S_{\min }$ are the highest and lowest measured flux densities, respectively, and $\sigma_{\max }$ and $\sigma_{\min }$ are the uncertainties in these measurements. The variability index for the strongest features on a timescale of nearly two years, $v i_{2}$, is listed in Table 2. We restrict our analysis to sources with a peak flux density greater than $1 \mathrm{Jy}$ to eliminate spurious effects. For previously known objects, we estimated the variability indices relative to the 2008-2009 measurements of Avison et al. (2016) $\left(v i_{10}\right)$ and the 1993-1994 observations by Caswell \& Vaile (1995) $\left(v i_{25}\right)$. These variability indices are added to Table 2 and for sources with complex spectra the velocity and polarisation of the considered feature are given in the notes.

Of 25 sources with reliably estimated $v i_{2}, 8$ show little or no variation within the noise, 12 show moderate or significant variability $\left(0.1<v i_{2}<0.3\right)$, and 5 sources show large variability, that is, a factor of $\geq 2\left(v i_{2}>0.3\right)$. We note that all the newly detected sources show significant or high variability. We suggest that the considerable variability of G12.209-00.102, G25.710+0.044, and G28.146-0.005 is the cause of the non-detection in the more sensitive MMB survey (Avison et al. 2016).

The variability index of the main feature does not give the complete picture of variability for sources with complex spectra. Figure 3 shows the spectra of G12.209-00.102 at three epochs spanning almost 9 months. In July and December 2018, the shape of the spectrum in the velocity range of $15.5-20.2 \mathrm{~km} \mathrm{~s}^{-1}$ was preserved but it was completely rebuilt in April 2019 when the intensity decreased by a factor of seven and polarisation properties changed remarkably. Clearly detected emission at velocities higher than $24.7 \mathrm{~km} \mathrm{~s}^{-1}$ with a peak flux of $2.7 \mathrm{Jy}$ appeared only 
Table 2. Variability indices of $6035 \mathrm{MHz}$ emission for the main feature on timescales of $2\left(v i_{2}\right), 10\left(v i_{10}\right)$, and $25\left(v i_{25}\right)$ years.

\begin{tabular}{|c|c|c|c|}
\hline Source & $v i_{2}$ & $v i_{10}$ & $v i_{25}$ \\
\hline G10.320-00.259 & 0.04 & 0.02 & \\
\hline G10.958+00.022 & 0.02 & 0.12 & \\
\hline G11.034+00.062 & 0.04 & 0.03 & 0.79 \\
\hline G11.904-00.141 & 0.30 & 0.78 & 0.78 \\
\hline G12.209-00.102 & 0.72 & & \\
\hline G12.681-00.182 & 0.42 & 0.73 & \\
\hline G15.035-00.677 (1),(2) & 0.06 & 0.40 & 0.48 \\
\hline G20.237+00.065 & 0.30 & 0.24 & 0.35 \\
\hline G24.148-00.009 & 0.34 & 0.54 & \\
\hline G25.650+01.049 & 0.03 & 0.09 & \\
\hline G25.710+00.044 & 0.21 & & \\
\hline G28.146-00.005 & 0.25 & & \\
\hline G28.201-00.049 & & 0.31 & 0.34 \\
\hline G30.771-00.804 & & 0.08 & \\
\hline G34.257+00.153 ${ }^{(3),(2)}$ & & 0.46 & 0.70 \\
\hline G34.267-00.210 & 0.02 & & \\
\hline G35.025+00.350 & 0.18 & 0.26 & 0.44 \\
\hline G43.149+00.013 & 0.12 & 0.16 & 0.44 \\
\hline $\mathrm{G} 45.467+00.053^{(4)}$ & 0.02 & 0.10 & 0.20 \\
\hline G48.990-00.299 & 0.16 & 0.20 & \\
\hline G49.490-00.388 & 0.02 & 0.24 & 0.67 \\
\hline G80.861+00.383 & 0.39 & & \\
\hline G81.871+00.781 (6) & 0.18 & & \\
\hline G85.410+00.003 & 0.17 & & \\
\hline G108.766-00.986 & 0.22 & & \\
\hline G111.542+00.777 & 0.28 & & \\
\hline G133.947+01.064 ${ }^{(7)}$ & 0.11 & & \\
\hline G183.348-00.575 & 0.53 & & \\
\hline
\end{tabular}

Notes. For sources with complex spectra, the velocity and polarisation of the feature used are noted. New detections are in bold. ${ }^{(1)} 21.5 \mathrm{~km} \mathrm{~s}^{-1}$ LHC; (2) large changes in the spectrum shape; (3) $58.4 \mathrm{~km} \mathrm{~s}^{-1}$ RHC; (4) $66.38 \mathrm{~km} \mathrm{~s}^{-1} \quad$ LHC; (5) $55.0 \mathrm{~km} \mathrm{~s}^{-1}$ RHC; (6) $7.87 \mathrm{~km} \mathrm{~s}^{-1}$ RHC; (7) $-43.3 \mathrm{~km} \mathrm{~s}^{-1}$ LHC.

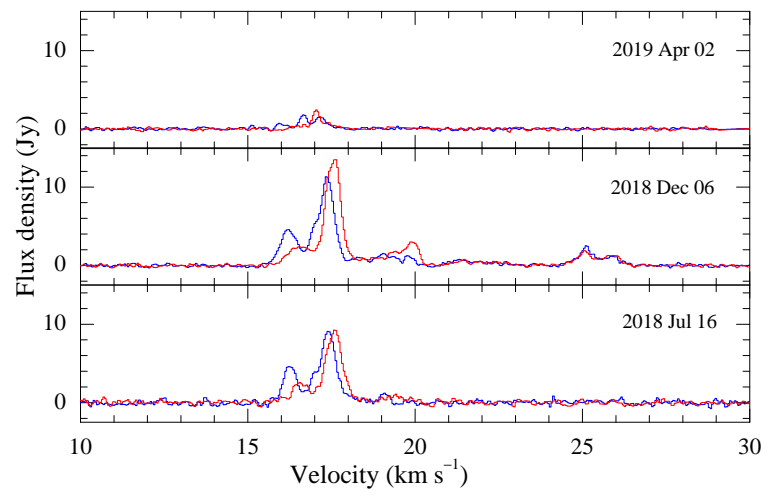

Fig. 3. OH $6035 \mathrm{MHz}$ spectra of G12.209-00.102 at three epochs. Blue and red lines denote LHC and RHC polarisation, respectively.

in December 2018. This case proves that remarkable variations of $\mathrm{OH} 6035 \mathrm{MHz}$ emission occur on timescales of less than 4 months. No significant variations in a 6 month interval were reported by Caswell \& Vaile (1995).

A general trend can be seen in terms of an increase in variability index with increasing timescales (Table 2). Figure 4 shows the light curve of the main feature in G15.035-00.677.

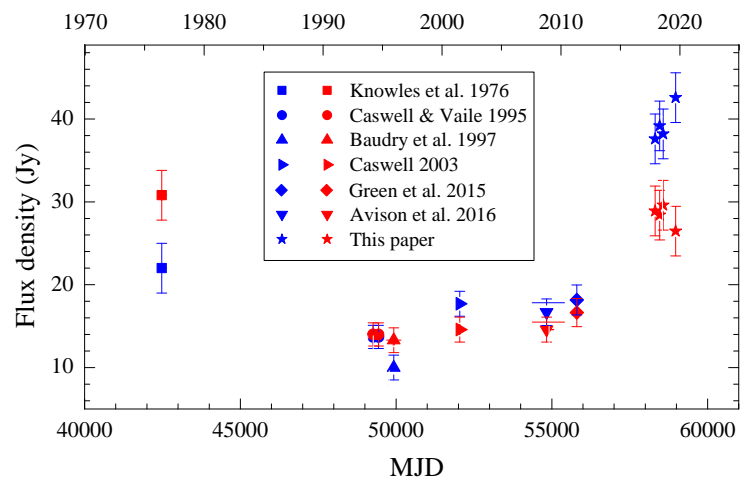

Fig. 4. Long term variability of the main feature $\left(21.5 \mathrm{~km} \mathrm{~s}^{-1}\right)$ of G015.035-00.677 at $6035 \mathrm{MHz}$. Blue and red symbols denote LHC and RHC polarisation, respectively.

The first published spectrum with the flux density scale was obtained in 1975 (Knowles et al. 1976) and contains two spectral features; the most prominent of the two corresponds to our $21.45 \mathrm{~km} \mathrm{~s}^{-1}$ feature and the emission in RHC polarisation was stronger than that in LHC polarisation. The RHC flux density of this latter feature decreased by a factor of 2.2 after $18.6 \mathrm{yr}$ (Caswell \& Vaile 1995), and then remained stable within $15 \%$ over a period of $18 \mathrm{yr}$ and increased by a factor of two after $10 \mathrm{yr}$. The LHC flux density followed the same course. During a low plateau state the difference between polarisation diminished and then the LHC signal became dominant. The flux ratio of the 21.45 and $22.65 \mathrm{~km} \mathrm{~s}^{-1}$ features varied from 1.8 (Knowles et al. 1976) to 0.96 (Caswell 2003) and then to 2.1 during our observations. The case of G15.035-00.677 depicts significant variations in the intensity, spectrum shape, and polarisation over a period of $45 \mathrm{yr}$. We note significant changes on a similar timescale for the 6035 and $6031 \mathrm{MHz}$ masers of G133.947+01.064 (W3OH) when comparing our spectra with those reported in the literature (e.g. Moran et al. 1978; Desmurs \& Baudry 1998; Fish \& Sjouwerman 2007).

\subsection{Unusual flux ratio in G49.490-00.388}

Towards the G49.490-00.388 site, the $\mathrm{OH}$ emission near the velocity of $52.4 \mathrm{~km} \mathrm{~s}^{-1}$ shows striking characteristics; the $6031 / 6035 \mathrm{MHz}$ flux density ratio exceeds unity for almost the total width of the profile, reaching a peak value of 3.4 and 3.1 for LHC and RHC polarisation, respectively (Fig. 5). This phenomenon in the source was discussed by Caswell (2003) who also noted similar properties in G345.010+01.792 and G353.410-00.360 observed by Smits (1994), but in the first of them this feature was short lived (Caswell 2003). Baudry et al. (1997) noted the well-known source G109.871+2.114 (Cep A) as the exceptional case with the 6031/6035 flux ratio of order unity. This source probably shows significant variability and was not detected in the present survey.

In G49.490-00.388, the line profiles of both transitions match in velocity and polarisation. A magnetic field strength derived from the velocity separation of peaks in each sense of circular polarisation is $+4.8 \pm 0.3$ and $+5.2 \pm 0.4 \mathrm{mG}$ for 6031 and $6035 \mathrm{MHz}$, respectively, and is consistent with that observed $\sim 18 \mathrm{yr}$ ago but at a velocity near $53.2 \mathrm{~km} \mathrm{~s}^{-1}$ (Caswell 2003). Avison et al. (2016) reported the MMB observations taken in 2008-2009 where $6031 \mathrm{MHz}$ RHC polarised emission at $52.7 \mathrm{~km} \mathrm{~s}^{-1}$ is stronger by a factor of 1.3 than the counterpart emission at $6035 \mathrm{MHz}$. The data from 1994 suggest a similar flux ratio (Baudry et al. 1997; Desmurs \& Baudry 1998). In 


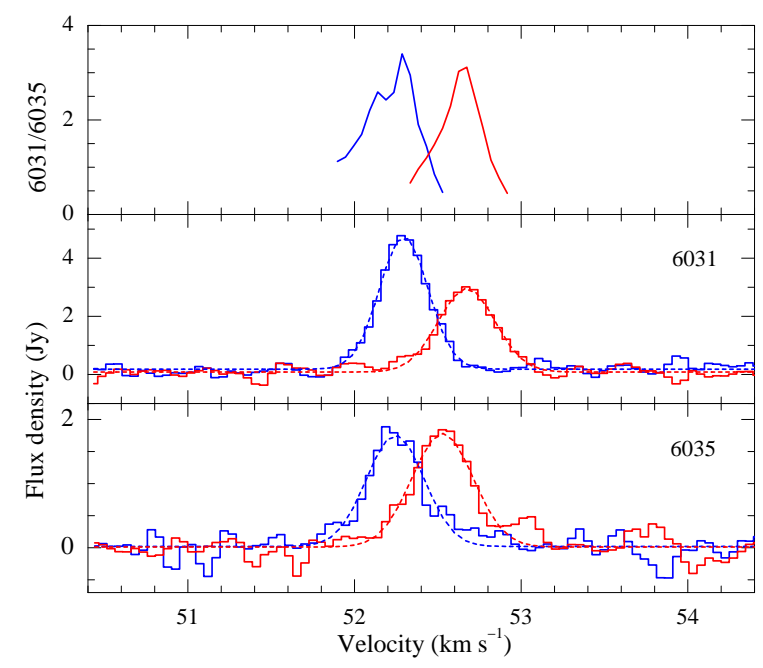

Fig. 5. Part of $\mathrm{OH}$ spectra in G49.490-00.388 showing a rare case where the maser intensity at $6031 \mathrm{MHz}$ surpasses that at $6035 \mathrm{MHz}$. Upper panel: line ratio for each polarisation. Blue and red lines are LHC and RHC polarisation, respectively. The dashed lines correspond to the Gaussian fits.

turn, the spectra from 1973 imply a ratio of 0.6 and 0.4 for the LHC and RHC polarisation, respectively, when the profiles were seen near $53.2 \mathrm{~km} \mathrm{~s}^{-1}$ (Rickard et al. 1975). The magnetic field strength estimates at that epoch of +4.1 to $+5.7 \mathrm{mG}$ are fully consistent with ours. We conclude that the flux ratio of the feature varies considerably, exceeding unity for a period of at least $25 \mathrm{yr}$. This emission appeared at slightly different velocities and the spectra taken at four epochs: 1994 (Baudry et al. 1997; Desmurs \& Baudry 1998), 2001 (Caswell 2003), 2008-2009 (Avison et al. 2016), and 2019 (this paper) suggest a velocity drift of $0.03 \mathrm{~km} \mathrm{~s}^{-1} \mathrm{yr}^{-1}$.

High-angular-resolution observations of a few sources revealed a good match of positions between the 6031 and $6035 \mathrm{MHz}$ maser components (Desmurs \& Baudry 1998; Desmurs et al. 1998; Etoka et al. 2005) suggesting copropagation of both lines. According to model calculations, these transitions probe the gas for low gas temperature $(<70 \mathrm{~K})$, high density $\left(3 \times 10^{7-8} \mathrm{~cm}^{-3}\right)$, and $\mathrm{OH}$ column densities greater than $2 \times 10^{17} \mathrm{~cm}^{-2}$ (Cragg et al. 2002). In the models of these latter authors, the $6031 \mathrm{MHz}$ line closely accompanies the $6035 \mathrm{MHz}$ line but is usually weaker. This prediction is consistent with observations for which the typical value of the peak flux ratio of 6031/6035 ranges from 0.14 to 0.5 (Baudry et al. 1997; Caswell 2003; Avison et al. 2016). Thus, the excess of $6031 \mathrm{MHz}$ emission in G49.490-00.388 could be produced under some special conditions that could be extremely rare or transient (Caswell 2003) and that have not been explored in models. As the ratio increased over more than four decades and the profile slightly drifts in velocity, the maser may emerge from a region accelerated by stellar wind or outflow where physical conditions are readily deviating from typical parameters tested in the maser models (Cragg et al. 2002).

\section{Conclusions}

The detection rate of excited-state $\mathrm{OH}$ transition of $6 \%$ implies a rare association of $\mathrm{OH} 6035 \mathrm{MHz}$ and $\mathrm{CH}_{3} \mathrm{OH} 6668 \mathrm{MHz}$ masers. Nevertheless, we identified three objects with possible co-propagation of both transitions. For these sources, the ratio of $\mathrm{CH}_{3} \mathrm{OH} / \mathrm{OH}$ isotropic luminosities is only between two and three and may indicate the gas cloudlets with a narrow range of gas density of about $10^{8} \mathrm{~cm}^{-3}$ and low kinetic temperature of $<50 \mathrm{~K}$. This possibility needs to be examined with high-angular-resolution observations.

All the newly detected $\mathrm{OH}$ maser sources show variability greater than a factor of 1.4-6.1 on timescales of 4-20 months while their non-detection in previous more sensitive surveys suggests extraordinary variations on timescales of several years. For previously known sources, we saw a general trend of an increase in variability index for longer (10-25 yr) timescales.

A rare case of a source with the maser intensity at $6031 \mathrm{MHz}$ surpassing that at $6035 \mathrm{MHz}$ was confirmed. Inspection of the available data revealed one feature with considerable variations of the 6031/6035 flux ratio, exceeding unity for a period of $25 \mathrm{yr}$. This phenomenon cannot be explained by the standard models but observational characteristics such as a drift in velocity suggest that it occurs in a region accelerated by stellar wind or outflow. Further monitoring and interferometric studies are required to understand this unusual case.

Acknowledgements. The $32 \mathrm{~m}$ radio telescope is operated by the Institute of Astronomy, Nicolaus Copernicus University and supported by the Polish Ministry of Science and Higher Education SpUB grant. We thank the staff and students for assistance with the observations. This research has made use of the SIMBAD data base, operated at CDS (Strasbourg, France) and NASA's Astrophysics Data System Bibliographic Services. We acknowledge support from the Polish National Science Centre grant 2016/21/B/ST9/01455.

\section{References}

Anglada, G., Rodríguez, L. F., \& Carrasco-González, C. 2018, A\&ARv, 26, 3 Argon, A. L., Reid, M. J., \& Menten, K. M. 2000, ApJS, 129, 159

Avison, A., Quinn, L. J., Fuller, G. A., et al. 2016, MNRAS, 461, 136 Avison, A., Quinn, L. J., Fuller, G. A., et al. 2020, MNRAS, 495, 3839 Baudry, A., Desmurs, J. F., Wilson, T. L., \& Cohen, R. J. 1997, A\&A, 325, 255 Beltrán, M. T., \& de Wit, W. J. 2016, A\&ARv, 24, 6

Beuther, H., Walsh, A., Wang, Y., et al. 2019, A\&A, 628, A90

Breen, S. L., Fuller, G. A., Caswell, J. L., et al. 2015, MNRAS, 450, 4109

Caswell, J. L. 1997, MNRAS, 289, 203

Caswell, J. L. 1999, MNRAS, 308, 683

Caswell, J. L. 2001, MNRAS, 326, 805

Caswell, J. L. 2003, MNRAS, 341, 551

Caswell, J. L. 2009, PASA, 26, 454

Caswell, J. L., \& Vaile, R. A. 1995, MNRAS, 273, 328

Cragg, D. M., Sobolev, A. M., \& Godfrey, P. D. 2002, MNRAS, 331, 521

Desmurs, J. F., \& Baudry, A. 1998, A\&A, 340, 521

Desmurs, J. F., Baudry, A., Wilson, T. L., Cohen, R. J., \& Tofani, G. 1998, A\&A, 334, 1085

Edris, K. A., Fuller, G. A., \& Cohen, R. J. 2007, A\&A, 465, 865

Etoka, S., Cohen, R. J., \& Gray, M. D. 2005, MNRAS, 360, 1162

Fish, V. L., \& Sjouwerman, L. O. 2007, ApJ, 668, 331

Forster, J. R., \& Caswell, J. L. 1999, A\&AS, 137, 43

Green, J. A., Caswell, J. L., Fuller, G. A., et al. 2010, MNRAS, 409, 913

Green, J. A., Caswell, J. L., \& McClure-Griffiths, N. M. 2015, MNRAS, 451, 74

Hu, B., Menten, K. M., Wu, Y., et al. 2016, ApJ, 833, 18

Knowles, S. H., Caswell, J. L., \& Goss, W. M. 1976, MNRAS, 175, 537

Menten, K. M. 1991, ApJ, 380, L75

Moran, J. M., Reid, M. J., Lada, C. J., et al. 1978, ApJ, 224, L67

Pavlakis, K. G., \& Kylafis, N. D. 2000, ApJ, 534, 770

Persi, P., Tapia, M., \& Gómez, M. 2011, A\&A, 525, A1

Qiao, H.-H., Breen, S. L., Gómez, J. F., et al. 2020, ApJS, 247, 5

Rickard, L. J., Zuckerman, B., \& Palmer, P. 1975, ApJ, 200, 6

Smits, D. P. 1994, MNRAS, 269, L11

Szymczak, M., \& Kus, A. J. 2000, A\&AS, 147, 181

Szymczak, M., Wolak, P., Bartkiewicz, A., \& Borkowski, K. M. 2012, Astron. Nachr., 333, 634

Szymczak, M., Olech, M., Sarniak, R., Wolak, P., \& Bartkiewicz, A. 2018, MNRAS, 474, 219

Urquhart, J. S., Hoare, M. G., Purcell, C. R., et al. 2009, A\&A, 501, 539

Urquhart, J. S., Morgan, L. K., Figura, C. C., et al. 2011, MNRAS, 418, 1689

Wu, Y. W., Xu, Y., Pandian, J. D., et al. 2010, ApJ, 720, 392

Yen, J. L., Zuckerman, B., Palmer, P., \& Penfield, H. 1969, ApJ, 156, L27

Zinnecker, H., \& Yorke, H. W. 2007, ARA\&A, 45, 481 
Appendix A: Supplementary materials
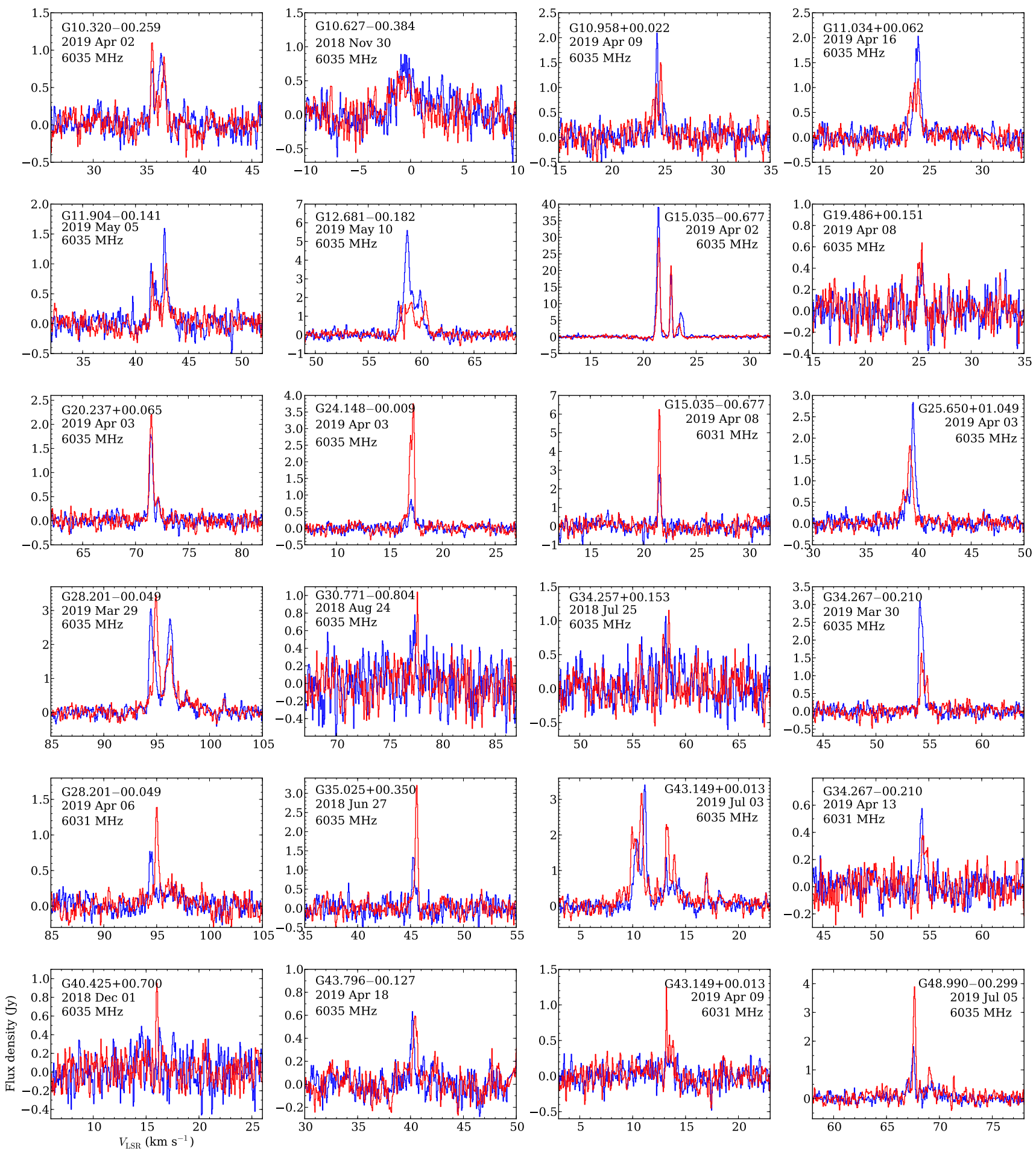

Fig. A.1. 6035 and $6031 \mathrm{MHz}$ OH maser spectra as detected in the Torun survey. Red and blue lines are RHC and LHC polarisations, respectively. 
A\&A 642, A145 (2020)
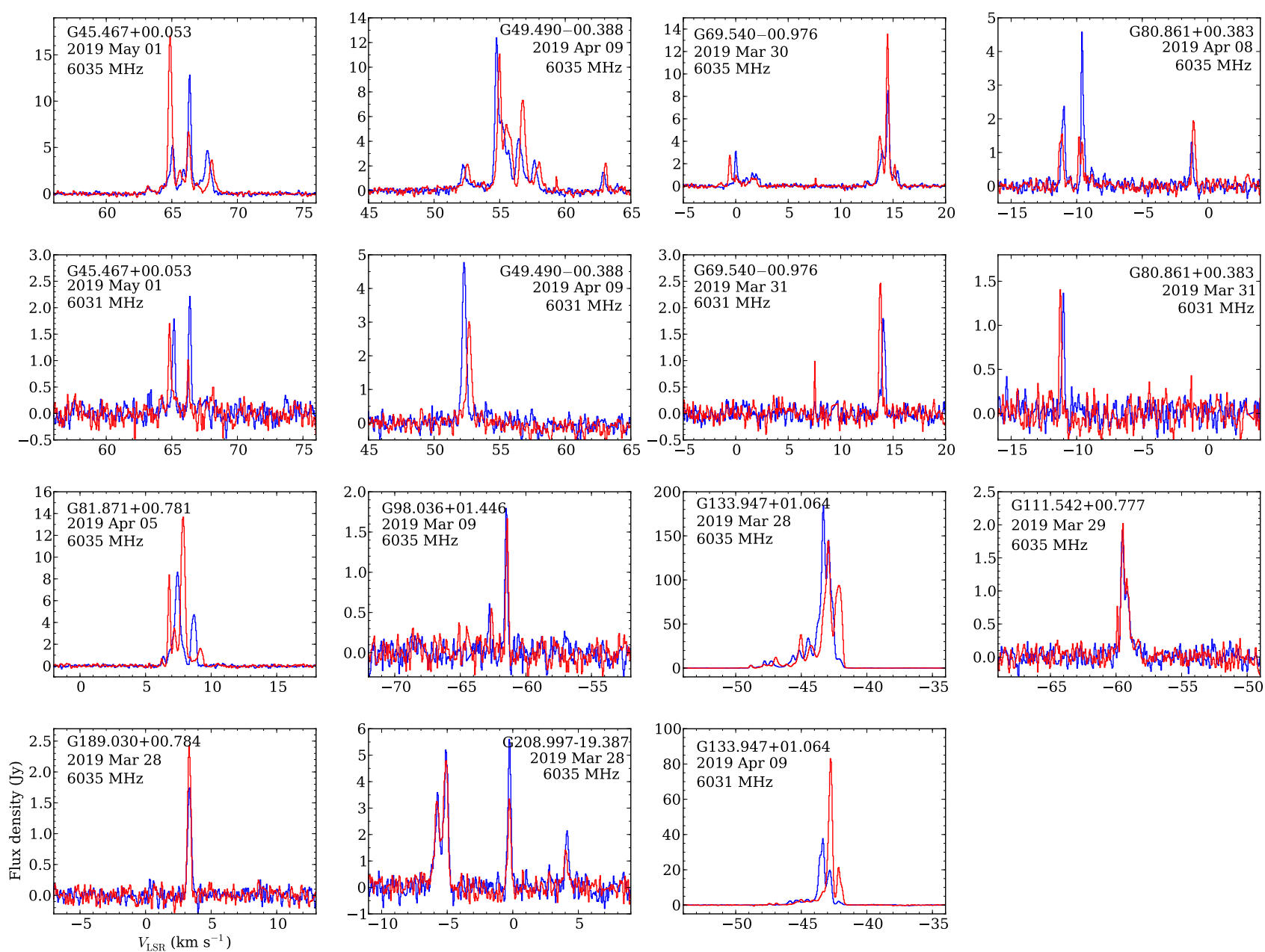

Fig. A.1. continued. 
Table A.1. Properties of 6035 and $6031 \mathrm{MHz} \mathrm{OH}$ maser emission for previously known sources.

\begin{tabular}{|c|c|c|c|c|c|c|c|c|c|}
\hline \multirow[b]{2}{*}{ Name (l b) } & \multirow[b]{2}{*}{ RA (J2000) } & \multirow[b]{2}{*}{ Dec (J2000) } & \multirow{3}{*}{$\begin{array}{c}\Delta V \\
\left(\mathrm{~km} \mathrm{~s}^{-1}\right)\end{array}$} & \multicolumn{3}{|c|}{ LHC } & \multicolumn{3}{|c|}{ RHC } \\
\hline & & & & \multirow{2}{*}{$\begin{array}{c}V_{\mathrm{p}} \\
\left(\mathrm{km} \mathrm{s}^{-1}\right)\end{array}$} & \multirow{2}{*}{$\begin{array}{c}S_{\mathrm{p}} \\
(\mathrm{Jy})\end{array}$} & \multirow{2}{*}{$\begin{array}{c}S_{\mathrm{i}} \\
\left(\mathrm{Jy} \mathrm{km} \mathrm{s}^{-1}\right)\end{array}$} & \multirow{2}{*}{$\begin{array}{c}V_{\mathrm{p}} \\
\left(\mathrm{km} \mathrm{s}^{-1}\right)\end{array}$} & \multirow{2}{*}{$\begin{array}{l}S_{\mathrm{p}} \\
(\mathrm{Jy})\end{array}$} & \multirow{2}{*}{$\begin{array}{c}S_{\mathrm{i}} \\
\left(\mathrm{Jy} \mathrm{km} \mathrm{s}^{-1}\right)\end{array}$} \\
\hline$\left(^{\circ}\right.$ & $\left(\begin{array}{lll}h & m & s\end{array}\right)$ & $\left({ }^{\circ},{ }^{\prime}, \prime\right)$ & & & & & & & \\
\hline G10.320-00.259 & 180923.30 & -200806.90 & $35.3 ; 37.2$ & 36.41 & 0.96 & 0.97 & 35.59 & 1.10 & 0.69 \\
\hline G10.627-00.384 & 181029.22 & -195541.10 & $-2.2 ; 1.1$ & -0.91 & 0.89 & 2.02 & -1.24 & 0.64 & 1.20 \\
\hline G10.958+00.022 & 180939.32 & -192628.00 & $23.8 ; 25.3$ & 24.32 & 2.10 & 0.77 & 24.66 & 1.50 & 0.70 \\
\hline G11.034+00.062 & 180939.84 & -192120.30 & $23.0 ; 24.5$ & 23.99 & 2.03 & 1.27 & 23.99 & 1.18 & 0.94 \\
\hline G11.904-00.141 & 181211.44 & -184128.60 & $41.3 ; 43.7$ & 42.74 & 1.60 & 1.28 & 42.94 & 1.01 & 0.88 \\
\hline G12.681-00.182 & 181354.75 & -180146.60 & $57.6 ; 60.8$ & 58.69 & 5.59 & 5.83 & 60.39 & 1.82 & 2.91 \\
\hline \multirow[t]{2}{*}{ G15.035-00.677 } & 182024.78 & -161134.60 & $21.0 ; 23.9$ & 21.42 & 39.04 & 20.48 & 21.46 & 29.81 & 16.34 \\
\hline & 6031 & & $21.3 ; 21.8$ & 21.51 & 6.25 & 1.49 & & 2.78 & 0.74 \\
\hline G19.486+00.151 & 182600.39 & -115222.60 & $24.7,25.7$ & 25.40 & 0.45 & 0.19 & 25.35 & 0.64 & 0.25 \\
\hline $\mathrm{G} 20.237+00.065$ & 182744.56 & -111454.30 & $71.07 ; 72.5$ & 71.42 & 1.79 & 0.83 & 71.51 & 2.20 & 1.03 \\
\hline G24.148-00.009 & 183520.94 & -074855.67 & $16.3 ; 17.7$ & 17.06 & 0.87 & 0.35 & 17.25 & 3.75 & 1.73 \\
\hline G25.650+01.049 & 183420.90 & -055942.20 & $38.1 ; 40.2$ & 39.52 & 2.84 & 0.16 & 39.23 & 1.83 & 1.28 \\
\hline \multirow[t]{2}{*}{ G28.201-00.049 } & 184258.08 & -041356.20 & $94.0 ; 98.9$ & 94.46 & 3.05 & 4.20 & 94.94 & 3.45 & 4.04 \\
\hline & 6031 & & & 94.30 & 0.77 & 0.76 & 95.04 & 1.39 & 0.95 \\
\hline G30.771-00.804 & 185021.55 & -021724.00 & $76.8,77.9$ & 77.41 & 0.78 & 0.27 & 77.65 & 1.04 & 0.20 \\
\hline $\mathrm{G} 34.257+00.153$ & 185318.63 & +011457.40 & $57.5 ; 58.7$ & 58.14 & 1.06 & 0.25 & 58.43 & 1.15 & 0.50 \\
\hline \multirow[t]{2}{*}{ G34.267-00.210 } & 185437.25 & +010533.70 & $53.9 ; 55.0$ & 54.16 & 3.09 & 1.47 & 54.31 & 1.64 & 0.82 \\
\hline & 6031 & & $53.9 ; 5$ & 54.35 & 0.58 & 0.23 & 54.40 & 0.38 & 0.16 \\
\hline G35.025+00.350 & 185400.66 & +020119.30 & $45.1 ; 45.7$ & 45.21 & 1.33 & 0.45 & 45.60 & 3.21 & 0.85 \\
\hline G40.425+00.700 & 190239.62 & 065910.50 & $15.8 ; 16.1$ & - & - & 0.05 & 16.03 & 0.95 & 0.15 \\
\hline \multirow[t]{2}{*}{$\mathrm{G} 43.149+00.013$} & 191011.05 & +090520.40 & $8.5 ; 18.6$ & 11.15 & 3.41 & 3.95 & 10.86 & 3.17 & 5.67 \\
\hline & 6031 & & $12.9 ; 14.0$ & - & - & 0.16 & 13.19 & 1.25 & 0.37 \\
\hline G43.796-00.127 & 191153.97 & 53.50 & $39.8 ; 40.7$ & 40.18 & 0.63 & 0.22 & 40.43 & 0.60 & 0.35 \\
\hline \multirow[t]{2}{*}{$\mathrm{G} 45.467+00.053$} & 191424.15 & +110943.00 & $62.7 ; 68.6$ & 66.38 & 12.82 & 10.63 & 64.87 & 17.06 & 12.16 \\
\hline & 6031 & & $63.9 ; 68.3$ & 66.38 & 2.22 & 1.03 & 64.83 & 1.70 & 0.94 \\
\hline G48.990-00.299 & 192226.13 & +140639.78 & $66.7 ; 69.6$ & 67.55 & 1.81 & 1.34 & 67.65 & 3.89 & 1.96 \\
\hline \multirow[t]{2}{*}{ G49.490-00.388 } & 192343.95 & +143034.20 & $52.1 ; 63.3$ & 54.76 & 12.39 & 13.25 & 55.00 & 11.07 & 14.80 \\
\hline & 6031 & & 52.1 & 52.28 & 4.77 & 1.93 & 52.67 & 3.01 & 1.40 \\
\hline \multirow[t]{2}{*}{ G69.540-00.976 } & 201009.07 & +313134.86 & $-0.9 ; 15.7$ & 14.53 & 8.52 & 7.53 & 14.48 & 13.56 & 8.69 \\
\hline & 6031 & & $13.4 ; 14.3$ & 14.05 & 1.80 & 0.69 & 13.81 & 2.46 & 0.73 \\
\hline \multirow[t]{2}{*}{ G80.861+00.383 } & 203700.96 & +413455.70 & $-11.5 ;-0.8$ & -9.60 & 4.58 & 2.45 & -1.10 & 1.94 & 1.70 \\
\hline & 6031 & & $-11.2 ;-10.7$ & -11.01 & 1.37 & 0.28 & -11.26 & 1.40 & 0.19 \\
\hline G81.871+00.781 & 203836.42 & +423734.56 & $6.1 ; 9.5$ & 7.44 & 8.63 & 7.09 & 7.87 & 13.68 & 9.34 \\
\hline G98.036+01.446 & 214301.43 & +545617.75 & $-63.0 ;-61.3$ & -62.76 & 0.61 & 0.49 & -62.60 & 0.55 & 0.49 \\
\hline G111.542+00.777 & 231345.36 & +612810.55 & $-60.4 ;-58.1$ & -59.52 & 1.91 & 0.92 & -59.47 & 2.02 & 1.18 \\
\hline \multirow[t]{2}{*}{ G133.947+01.064 } & 022703.82 & +610225.4 & $-49.1 ;-41.1$ & -43.31 & 184.16 & 190.1 & -42.92 & 144.04 & 181.9 \\
\hline & 6031 & & $-47.7 ;-41.4$ & -43.35 & 37.72 & 30.84 & -42.77 & 83.04 & 45.85 \\
\hline G189.030+00.784 & 060840.67 & +213106.90 & $3.0 ; 3.7$ & 3.37 & 1.74 & 0.57 & 3.32 & 2.43 & 0.70 \\
\hline G208.997-19.387 & 053514.50 & -052245.00 & $-6.4 ; 4.6$ & -0.27 & 5.60 & 5.92 & -5.07 & 4.80 & 4.42 \\
\hline
\end{tabular}

Notes. The following parameters are listed; velocity range of $I$ Stokes emission $(\Delta V)$, peak velocity $\left(V_{\mathrm{p}}\right)$, peak flux density $\left(S_{\mathrm{p}}\right)$, and integrated flux density $\left(S_{\mathrm{i}}\right)$ for the LHC and RHC polarisations. 
Table A.2. Non-detections.

\begin{tabular}{|c|c|c|c|c|}
\hline \multirow{2}{*}{ Name $(1 \mathrm{~b})$} & RA (J200) & $\operatorname{Dec}(\mathrm{J} 2000)$ & \multirow{2}{*}{$\begin{array}{l}V_{\mathrm{c}}(6668) \\
\left(\mathrm{km} \mathrm{s}^{-1}\right)\end{array}$} & \multirow[t]{2}{*}{ Ref } \\
\hline & $\left(\begin{array}{lll}h & m & s\end{array}\right)$ & & & \\
\hline G08.317-00.096 & 180436.02 & 214819.60 & 46.9 & \\
\hline G08.669-00.356 & 180618.99 & -213732.20 & 39.2 & 1 \\
\hline G08.683-00.368 & 180623.49 & -213710.20 & 43.1 & \\
\hline G08.832-00.028 & 180525.66 & -211925.50 & -3.9 & \\
\hline G08.872-00.493 & 180715.32 & -213054.40 & 23.2 & \\
\hline G09.215-00.202 & 180652.84 & -210427.50 & 45.5 & \\
\hline G09.621+00.196 & 180614.67 & -203132.40 & 1.2 & 2 \\
\hline G09.619+00.193 & 180614.92 & -203144.30 & 5.5 & 2 \\
\hline G09.986-00.028 & 180750.12 & -201856.50 & 42.2 & \\
\hline G10.205-00.345 & 180928.43 & -201642.50 & 6.6 & \\
\hline G10.287-00.125 & 180849.36 & -200559.00 & 4.6 & \\
\hline G10.299-00.146 & 180855.54 & -200557.50 & 19.9 & \\
\hline G10.323-00.160 & 180901.46 & -200507.80 & 11.5 & \\
\hline G10.342-00.142 & 180859.99 & -200335.40 & 15.4 & \\
\hline G10.356-00.148 & 180903.07 & -200302.20 & 49.9 & \\
\hline G10.444-00.018 & 180844.88 & -195438.20 & 73.3 & \\
\hline G10.472+00.027 & 180838.20 & -195150.10 & 75.0 & \\
\hline $\mathrm{G} 10.480+00.033$ & 180837.88 & -195116.10 & 59.5 & \\
\hline G10.629-00.333 & 181017.98 & -195404.80 & -8.1 & \\
\hline G10.724-00.334 & 181030.03 & -194906.80 & -2.2 & \\
\hline G10.822-00.103 & 180950.52 & -193714.10 & 72.0 & \\
\hline G10.886+00.123 & 180907.98 & -192721.80 & 17.1 & \\
\hline G11.109-00.114 & 181028.25 & -192229.10 & 23.9 & \\
\hline G11.497-01.485 & 181622.13 & -194127.10 & 6.6 & \\
\hline G11.903-00.102 & 181202.70 & -184024.70 & 33.9 & \\
\hline G11.936-00.150 & 181217.29 & -184002.60 & 48.5 & \\
\hline G11.936-00.616 & 181400.89 & -185326.60 & 32.2 & \\
\hline G11.992-00.272 & 181251.19 & -184038.40 & 59.8 & \\
\hline G12.025-00.031 & 181201.86 & -183155.70 & 108.2 & \\
\hline G12.112-00.126 & 181233.39 & -183007.60 & 39.9 & \\
\hline G12.181-00.123 & 181241.00 & -182621.90 & 29.7 & \\
\hline G12.199-00.034 & 181223.44 & -182250.90 & 49.3 & \\
\hline G12.202-00.120 & 181242.93 & -182511.80 & 26.4 & \\
\hline G12.203-00.107 & 181240.24 & -182447.50 & 20.5 & \\
\hline G12.265-00.051 & 181235.40 & -181952.30 & 68.3 & \\
\hline G12.526+00.016 & 181252.04 & -180413.60 & 42.6 & \\
\hline G12.625-00.017 & 181311.30 & -175957.60 & 21.5 & \\
\hline G12.776+00.128 & 181257.57 & -174749.20 & 32.8 & \\
\hline G12.889+00.489 & 181151.40 & -173129.60 & 39.2 & \\
\hline G12.904-00.031 & 181348.27 & -174538.80 & 58.8 & \\
\hline G12.909-00.260 & 181439.53 & -175200.00 & 39.8 & \\
\hline G13.179+00.061 & 181400.96 & -172832.50 & 46.4 & \\
\hline G13.657-00.599 & 181724.27 & -172212.50 & 51.1 & \\
\hline G13.696-00.156 & 181551.05 & -170729.60 & 99.3 & \\
\hline G13.713-00.083 & 181536.99 & -170431.80 & 43.5 & \\
\hline G14.101+00.087 & 181545.80 & -163909.70 & 15.3 & \\
\hline G14.230-00.509 & 181812.59 & -164922.80 & 25.3 & \\
\hline G14.331-00.641 & 181853.80 & -164746.60 & 22.6 & \\
\hline G14.390-00.020 & 181643.77 & -162701.00 & 26.9 & \\
\hline G14.457-00.143 & 181718.79 & -162757.50 & 43.2 & \\
\hline
\end{tabular}

Notes. The central velocity $V_{\mathrm{c}}$ of observation is given. Previously known sources are bolded and reference for detection is given in the last column.

References. (1) Caswell \& Vaile (1995); (2) Avison et al. (2016); (3) Baudry et al. (1997).
Table A.2. continued.

\begin{tabular}{|c|c|c|c|c|}
\hline \multirow{2}{*}{ Name (1 b) } & RA (J200) & $\operatorname{Dec}(\mathrm{J} 2000)$ & \multirow{2}{*}{$\begin{array}{l}V_{\mathrm{c}}(6668) \\
\left(\mathrm{km} \mathrm{s}^{-1}\right)\end{array}$} & \multirow[t]{2}{*}{ Ref. } \\
\hline & $\left(\begin{array}{lll}h & m & s\end{array}\right)$ & $\left({ }^{\circ}, \quad, 1\right)$ & & \\
\hline G14.490+00.014 & 181648.06 & -162045.00 & 20.2 & \\
\hline $\mathrm{G} 14.521+00.155$ & 181620.73 & -161505.50 & 4.1 & \\
\hline G14.604+00.017 & 181701.14 & -161438.00 & 24.6 & \\
\hline G14.631-00.577 & 181915.21 & -163004.50 & 25.2 & \\
\hline G14.991-00.121 & 181817.32 & -155808.30 & 46.0 & \\
\hline G15.094+00.192 & 181720.82 & -154346.50 & 25.7 & \\
\hline G15.607-00.255 & 181959.34 & -152922.80 & 65.9 & \\
\hline G15.665-00.499 & 182059.75 & -153310.00 & -3.0 & \\
\hline G16.112-00.303 & 182109.14 & -150400.60 & 34.5 & \\
\hline G16.302-00.196 & 182107.83 & -145054.60 & 51.8 & \\
\hline G16.403-00.181 & 182116.39 & -144509.00 & 39.2 & \\
\hline G16.585-00.051 & 182109.13 & -143148.50 & 62.1 & \\
\hline G16.662-00.331 & 182219.46 & -143539.10 & 43.0 & \\
\hline $\mathrm{G} 16.831+00.079$ & 182109.53 & -141508.60 & 58.7 & \\
\hline G16.855+00.641 & 181909.57 & -135757.50 & 24.2 & \\
\hline G16.864-02.159 & 182924.42 & -151604.50 & 14.9 & \\
\hline G16.976-00.005 & 182144.68 & -140948.50 & 6.5 & \\
\hline G17.021-02.403 & 183036.30 & -151428.50 & 23.5 & \\
\hline G17.029-00.071 & 182205.21 & -140851.00 & 91.3 & \\
\hline G17.638+00.157 & 182226.30 & -133012.10 & 20.7 & \\
\hline G17.862+00.074 & 182310.10 & -132040.80 & 110.6 & \\
\hline G18.073+00.077 & 182333.98 & -130925.00 & 55.5 & \\
\hline G18.159+00.094 & 182340.18 & -130421.00 & 58.3 & \\
\hline G18.262-00.244 & 182505.70 & -130823.20 & 75.7 & \\
\hline $\mathrm{G} 18.341+01.768$ & 181758.13 & -120724.80 & 28.0 & \\
\hline G18.440+00.045 & 182423.32 & -125052.10 & 61.8 & \\
\hline G18.460-00.004 & 182436.34 & -125108.60 & 49.4 & 2 \\
\hline $\mathrm{G} 18.661+00.034$ & 182451.10 & -123922.50 & 79.0 & \\
\hline G18.667+00.025 & 182453.78 & -123920.80 & 78.7 & \\
\hline G18.733-00.224 & 182555.53 & -124248.90 & 45.8 & \\
\hline G18.735-00.227 & 182556.46 & -124250.00 & 37.9 & \\
\hline G18.834-00.300 & 182623.66 & -123938.00 & 41.1 & 2 \\
\hline G18.874+00.053 & 182511.34 & -122736.80 & 38.6 & \\
\hline G18.888-00.475 & 182707.85 & -124135.90 & 56.5 & \\
\hline G18.999-00.239 & 182629.24 & -122907.10 & 69.4 & \\
\hline G19.009-00.029 & 182544.77 & -122246.00 & 55.2 & \\
\hline G19.249+00.267 & 182508.02 & -120142.20 & 20.4 & \\
\hline $\mathrm{G} 19.267+00.349$ & 182452.38 & -115828.20 & 16.2 & \\
\hline G19.365-00.030 & 182625.78 & -120353.30 & 25.2 & \\
\hline G19.472+00.170 & 182554.70 & -115234.60 & 21.6 & \\
\hline G19.496+00.115 & 182609.16 & -115251.70 & 121.1 & \\
\hline G19.609-00.234 & 182737.99 & -115637.60 & 40.2 & \\
\hline G19.612-00.120 & 182713.48 & -115315.70 & 53.1 & \\
\hline G19.612-00.134 & 182716.52 & -115338.20 & 56.5 & \\
\hline G19.614+00.011 & 182645.24 & -114931.40 & 32.8 & \\
\hline G19.667+00.114 & 182628.97 & -114348.90 & 14.2 & \\
\hline G19.701-00.267 & 182755.52 & -115240.30 & 43.8 & \\
\hline G19.755-00.128 & 182731.66 & -114555.00 & 123.0 & 2 \\
\hline G19.884-00.534 & 182914.37 & -115023.00 & 46.7 & \\
\hline G20.081-00.135 & 182810.32 & -112847.60 & 43.5 & \\
\hline G20.364-00.013 & 182815.91 & -111020.40 & 55.9 & \\
\hline G20.733-00.059 & 182907.99 & -105200.60 & 60.7 & \\
\hline G20.926-00.050 & 182927.79 & -104128.80 & 27.4 & \\
\hline G20.963-00.075 & 182937.34 & -104012.60 & 34.6 & \\
\hline
\end{tabular}

A145, page 10 of 14 
Table A.2. continued.

\begin{tabular}{|c|c|c|c|c|}
\hline \multirow{2}{*}{$\begin{array}{c}\text { Name }\left(\begin{array}{l}1 \\
b\end{array}\right) \\
\left({ }^{\circ}{ }^{\circ}\right)\end{array}$} & RA (J200) & $\operatorname{Dec}(\mathrm{J} 2000)$ & \multirow{2}{*}{$\begin{array}{l}V_{\mathrm{c}}(6668) \\
\left(\mathrm{km} \mathrm{s}^{-1}\right)\end{array}$} & \multirow[t]{2}{*}{ Ref } \\
\hline & $\left(\begin{array}{lll}h & m & s\end{array}\right)$ & $\left({ }^{\circ},{ }^{\prime} \prime\right)$ & & \\
\hline G21.023-00.063 & 182941.55 & -103642.30 & 31.1 & \\
\hline G21.407-00.254 & 183106.33 & -10 2137.41 & 88.9 & \\
\hline G21.563-00.033 & 183036.07 & -100710.90 & 117.2 & \\
\hline G21.848-00.240 & 183153.06 & -095745.40 & 81.9 & \\
\hline G21.880+00.014 & 183101.75 & -094900.50 & 20.3 & \\
\hline G22.039+00.222 & 183034.70 & -093447.00 & 53.2 & \\
\hline G22.335-00.155 & 183229.40 & -092929.68 & 35.6 & \\
\hline $\mathrm{G} 22.357+00.066$ & 183144.12 & -092212.31 & 80.1 & \\
\hline G22.435-00.169 & 183243.82 & -092433.20 & 29.5 & 1 \\
\hline $\mathrm{G} 23.003+00.124$ & 183244.25 & -084610.70 & 110.5 & \\
\hline G23.010-00.411 & 183440.29 & -090038.10 & 74.7 & \\
\hline $\mathrm{G} 23.126+00.395$ & 183159.75 & -083209.10 & 13.8 & \\
\hline G23.207-00.377 & 183455.21 & -084914.89 & 81.6 & \\
\hline G23.257-00.241 & 183431.26 & -084246.70 & 63.9 & \\
\hline G23.365-00.291 & 183454.13 & -083825.60 & 82.5 & \\
\hline G23.389+00.185 & 183314.32 & -082357.47 & 75.3 & \\
\hline G23.437-00.184 & 183439.25 & -083138.50 & 102.9 & \\
\hline G23.440-00.182 & 183439.18 & -083125.40 & 96.6 & \\
\hline G23.484+00.097 & 183344.05 & -082120.60 & 87.0 & \\
\hline G23.657-00.127 & 183451.56 & -081821.30 & 82.4 & \\
\hline G23.707-00.198 & 183512.36 & -081739.36 & 76.4 & \\
\hline $\mathrm{G} 23.818+00.384$ & 183319.50 & -075538.10 & 76.2 & \\
\hline G23.885+00.060 & 183436.84 & -080100.70 & 45.0 & \\
\hline G23.901+00.077 & 183434.92 & -075942.20 & 35.7 & \\
\hline G23.966-00.109 & 183522.21 & -080122.47 & 70.8 & \\
\hline G23.986-00.089 & 183520.09 & -075945.00 & 65.1 & \\
\hline G23.996-00.100 & 183523.49 & -075929.80 & 68.2 & \\
\hline $\mathrm{G} 24.329+00.144$ & 183508.14 & -073504.00 & 110.3 & \\
\hline $\mathrm{G} 24.461+00.198$ & 183511.33 & -072631.10 & 125.5 & \\
\hline G24.493-00.039 & 183605.83 & -073120.60 & 115.0 & \\
\hline $\mathrm{G} 24.541+00.312$ & 183455.72 & -071906.65 & 105.5 & \\
\hline $\mathrm{G} 24.631+00.172$ & 183535.77 & -071808.75 & 115.9 & \\
\hline G24.634-00.324 & 183722.71 & -073142.14 & 35.5 & \\
\hline G24.676-00.150 & 183649.97 & -072442.10 & 116.1 & \\
\hline $\mathrm{G} 24.790+00.083$ & 183612.56 & -071210.79 & 113.3 & \\
\hline $\mathrm{G} 24.791+00.082$ & 183613.13 & -071208.20 & 105.8 & \\
\hline G24.850+00.087 & 183618.40 & -070851.00 & 110.0 & \\
\hline G24.920+00.088 & 183625.94 & -070507.80 & 53.3 & \\
\hline $\mathrm{G} 24.943+00.074$ & 183631.55 & -070416.80 & 53.2 & \\
\hline $\mathrm{G} 25.226+00.288$ & 183616.97 & -064318.30 & 42.0 & \\
\hline G25.270-00.434 & 183856.96 & -070049.20 & 65.9 & \\
\hline G25.382-00.182 & 183815.20 & -064756.20 & 58.2 & \\
\hline $\mathrm{G} 25.395+00.034$ & 183730.28 & $-0641 \quad 17.70$ & 95.4 & \\
\hline G25.407-00.170 & 183815.52 & -064616.70 & 60.8 & \\
\hline G25.411+00.105 & 183716.92 & -063830.50 & 97.2 & \\
\hline G25.494+00.062 & 183735.44 & -063513.40 & 103.8 & \\
\hline $\mathrm{G} 25.613+00.226$ & 183713.42 & -062424.20 & 110.1 & \\
\hline G25.826-00.178 & 183903.63 & -062409.70 & 91.7 & \\
\hline G25.838-00.378 & 183947.88 & -062900.90 & -1.6 & \\
\hline G25.920-00.141 & 183906.07 & -061804.70 & 114.8 & \\
\hline G26.422+01.685 & 183330.51 & -050102.00 & 31.0 & \\
\hline $\mathrm{G} 26.545+00.423$ & 183814.46 & -052916.80 & 82.5 & \\
\hline G26.527-00.267 & 184040.26 & -054912.90 & 104.2 & \\
\hline G26.552-00.309 & 184052.03 & -054902.56 & 105.3 & \\
\hline
\end{tabular}

Table A.2. continued.

\begin{tabular}{|c|c|c|c|c|}
\hline \multirow{2}{*}{$\begin{array}{c}\text { Name }(1 \mathrm{~b}) \\
\left({ }^{\circ} \quad{ }^{\circ}\right)\end{array}$} & RA (J200) & $\operatorname{Dec}(\mathrm{J} 2000)$ & \multirow{2}{*}{$\begin{array}{l}V_{\mathrm{c}}(6668) \\
\left(\mathrm{km} \mathrm{s}^{-1}\right)\end{array}$} & \multirow[t]{2}{*}{ Ref. } \\
\hline & $\left(\begin{array}{lll}h & m & s\end{array}\right)$ & & & \\
\hline G26.598-00.024 & 183955.92 & -053844.64 & 24.8 & \\
\hline G26.601-00.221 & 184038.57 & -054401.60 & 103.4 & \\
\hline G26.648+00.018 & 183952.68 & -053454.60 & 109.4 & \\
\hline G27.011-00.039 & 184044.88 & -051709.80 & -18.3 & \\
\hline G27.221+00.136 & 184030.54 & -050105.39 & 118.8 & \\
\hline G27.286+00.151 & 184034.51 & -045714.40 & 34.8 & \\
\hline G27.365-00.166 & 184151.06 & -050143.50 & 99.8 & \\
\hline G27.500+00.107 & 184107.38 & -044702.30 & 87.3 & \\
\hline G27.757+00.050 & 184147.99 & -043452.60 & 99.2 & \\
\hline G27.783-00.259 & 184256.96 & -044159.00 & 98.3 & \\
\hline G27.784+00.057 & 184149.58 & -043313.80 & 111.9 & \\
\hline G27.869-00.235 & 184301.55 & -043643.10 & 20.1 & \\
\hline G28.011-00.426 & 184357.96 & -043421.90 & 16.9 & \\
\hline $\mathrm{G} 28.226+00.359$ & 184133.57 & -040122.34 & 49.7 & \\
\hline G28.282-00.359 & 184413.26 & -041804.80 & 41.3 & \\
\hline G28.321-00.011 & 184303.11 & -040626.40 & 104.8 & \\
\hline $\mathrm{G} 28.397+00.081$ & 184251.98 & -035953.60 & 71.5 & \\
\hline $\mathrm{G} 28.523+00.127$ & 184255.89 & -035155.40 & 39.6 & \\
\hline G28.532+00.129 & 184256.50 & -035121.60 & 27.0 & \\
\hline $\mathrm{G} 28.608+00.018$ & 184328.52 & -035022.80 & 106.4 & \\
\hline G28.687-00.283 & 184441.54 & -035422.10 & 92.3 & \\
\hline $\mathrm{G} 28.700+00.406$ & 184215.57 & -033446.90 & 94.2 & \\
\hline G28.817+00.365 & 184237.34 & -032940.92 & 90.7 & 2 \\
\hline G28.832-00.253 & 184451.08 & -034548.50 & 91.8 & \\
\hline $\mathrm{G} 28.842+00.493$ & 184212.54 & -032451.10 & 83.2 & \\
\hline G28.848-00.228 & 184447.46 & -034417.20 & 102.8 & \\
\hline G28.861+00.065 & 184346.24 & -033533.40 & 105.3 & \\
\hline G28.929+00.019 & 184403.56 & -033311.83 & 47.1 & \\
\hline G29.282-00.330 & 184556.96 & -032356.54 & 92.1 & \\
\hline G29.320-00.162 & 184525.16 & -031716.90 & 48.9 & \\
\hline $\mathrm{G} 29.581+00.133$ & 184450.92 & -025515.92 & 31.7 & \\
\hline G29.603-00.625 & 184735.41 & -031450.10 & 80.5 & \\
\hline G29.724+00.107 & 184511.97 & -024821.59 & 95.8 & \\
\hline G29.863-00.044 & 184559.57 & -024504.40 & 101.4 & \\
\hline G29.915-00.023 & 184600.94 & -024142.26 & 103.0 & \\
\hline G29.955-00.016 & 184603.74 & -023922.20 & 96.0 & \\
\hline G29.961-00.067 & 184615.36 & -024028.81 & 100.5 & \\
\hline G29.978-00.047 & 184612.96 & -023901.40 & 96.9 & \\
\hline G29.993-00.282 & 184704.82 & -024439.80 & 103.2 & \\
\hline G30.010-00.273 & 184704.71 & -024331.20 & 106.1 & \\
\hline G30.198-00.169 & 184703.04 & -023036.40 & 108.2 & \\
\hline G30.225-00.180 & 184708.30 & -022928.90 & 113.2 & \\
\hline $\mathrm{G} 30.317+00.070$ & 184625.02 & -021740.75 & 36.1 & \\
\hline G30.370+00.482 & 184502.72 & -020333.70 & 12.4 & \\
\hline G30.400-00.296 & 184752.30 & -022316.05 & 98.2 & \\
\hline G30.419-00.232 & 184740.76 & -022030.10 & 102.9 & \\
\hline $\mathrm{G} 30.423+00.466$ & 184512.08 & -020113.60 & 7.5 & \\
\hline G30.542+00.011 & 184702.26 & -020717.70 & 53.1 & \\
\hline G30.582-00.141 & 184739.20 & -020919.00 & 115.5 & \\
\hline G30.589-00.043 & 184718.86 & -020617.20 & 43.0 & \\
\hline G30.622+00.082 & 184655.78 & -020107.18 & 39.6 & \\
\hline G30.703-00.068 & 184736.82 & -020053.80 & 88.2 & \\
\hline
\end{tabular}


Table A.2. continued.

\begin{tabular}{|c|c|c|c|c|}
\hline \multirow{2}{*}{ Name $\left(\begin{array}{c}1 \\
b\end{array}\right)$} & RA (J200) & Dec (J2000) & \multirow{2}{*}{$\begin{array}{l}V_{\mathrm{c}}(6668) \\
\left(\mathrm{km} \mathrm{s}^{-1}\right)\end{array}$} & \multirow[t]{2}{*}{ Ref } \\
\hline & $\left(\begin{array}{lll}h & m & s\end{array}\right)$ & $\left({ }^{\circ}, \quad, \prime\right)$ & & \\
\hline G30.760-00.052 & 184739.78 & -015723.40 & 91.7 & \\
\hline G30.774+00.078 & 184713.42 & -015304.15 & 98.5 & \\
\hline G30.780+00.230 & 184641.52 & -014837.10 & 48.9 & \\
\hline G30.788+00.204 & 184648.09 & -014853.90 & 84.5 & \\
\hline G30.818-00.057 & 184746.97 & -015426.40 & 101.3 & \\
\hline G30.822-00.053 & 184746.53 & -015407.40 & 93.2 & \\
\hline $\mathrm{G} 30.851+00.123$ & 184712.26 & -014746.60 & 27.5 & \\
\hline G30.898+00.161 & 184709.13 & -014411.10 & 101.8 & \\
\hline G30.960+00.086 & 184732.00 & -014257.60 & 40.1 & \\
\hline G30.963+00.225 & 184702.62 & -013858.34 & 102.2 & \\
\hline G30.972-00.142 & 184822.07 & -014830.30 & 77.8 & \\
\hline G30.973+00.562 & 184551.69 & -012913.30 & 19.9 & \\
\hline G30.980+00.216 & 184706.47 & -013820.00 & 111.0 & \\
\hline G31.047+00.356 & 184643.85 & -013054.15 & 81.1 & \\
\hline $\mathrm{G} 31.059+00.093$ & 184741.35 & -013726.20 & 16.5 & \\
\hline G31.076+00.457 & 184625.44 & -012633.50 & 25.5 & \\
\hline G31.122+00.063 & 184754.68 & -013456.90 & 48.0 & \\
\hline G31.158+00.046 & 184802.40 & -013326.80 & 41.1 & \\
\hline G31.182-00.148 & 184846.41 & -013728.10 & 46.3 & \\
\hline $\mathrm{G} 31.253+00.003$ & 184821.92 & -012935.68 & 41.2 & \\
\hline G31.276+00.006 & 184823.79 & -012817.88 & 37.2 & \\
\hline G31.281+00.061 & 184812.43 & -012630.10 & 110.3 & \\
\hline G31.395-00.258 & 184933.09 & -012906.93 & 87.4 & \\
\hline G31.412+00.307 & 184734.29 & -011245.60 & 95.8 & \\
\hline $\mathrm{G} 31.581+00.077$ & 184841.94 & $-01 \quad 1002.53$ & 98.8 & \\
\hline G31.975+00.180 & 184903.05 & -004611.12 & 92.4 & \\
\hline $\mathrm{G} 32.045+00.059$ & 184936.56 & -004545.90 & 92.8 & \\
\hline G32.082+00.078 & 184936.60 & -004316.40 & 92.9 & \\
\hline G32.105-00.074 & 185011.58 & -004612.32 & 49.7 & \\
\hline G32.117+00.091 & 184937.70 & -004100.93 & 92.6 & \\
\hline $\mathrm{G} 32.516+00.323$ & 184931.74 & -00 1320.80 & 52.5 & \\
\hline G32.704-00.056 & 185113.22 & -001342.31 & 40.6 & \\
\hline G32.744-00.075 & 185121.87 & -001205.00 & 38.5 & 2 \\
\hline G32.802+00.193 & 185030.98 & -000139.00 & 27.2 & \\
\hline G32.821-00.330 & 185224.76 & -001456.87 & 82.1 & \\
\hline G32.825-00.328 & 185224.69 & -00 1439.70 & 82.4 & \\
\hline G32.914-00.096 & 185144.69 & -000335.50 & 103.5 & \\
\hline G32.917-00.094 & 185144.74 & -000320.16 & 103.2 & \\
\hline G32.963-00.340 & 185242.35 & -000739.10 & 46.7 & \\
\hline G32.965-00.340 & 185242.39 & -000732.97 & 48.1 & \\
\hline G32.992+00.034 & 185125.58 & 000408.33 & 91.9 & \\
\hline G33.093-00.073 & 185159.58 & 000635.50 & 103.9 & \\
\hline G33.133-00.092 & 185207.82 & 000812.80 & 73.2 & \\
\hline $\mathrm{G} 33.199+00.001$ & 185155.34 & 001419.38 & 91.2 & \\
\hline G33.204-00.010 & 185158.14 & 001413.61 & 91.9 & \\
\hline G33.317-00.360 & 185325.30 & 001043.90 & 28.1 & \\
\hline G33.393+00.010 & 185214.62 & 002452.90 & 105.2 & \\
\hline G33.424-00.315 & 185327.40 & 001740.64 & 45.6 & \\
\hline G33.486+00.040 & 185218.39 & 003040.20 & 121.7 & \\
\hline G33.641-00.228 & 185332.56 & 003139.18 & 60.3 & \\
\hline G33.634-00.021 & 185247.56 & 003654.20 & 103.1 & \\
\hline $\mathrm{G} 33.725-00.120$ & 185318.78 & 003905.00 & 54.1 & \\
\hline G33.852+00.018 & 185303.09 & 004936.50 & 61.0 & \\
\hline
\end{tabular}

Table A.2. continued.

\begin{tabular}{|c|c|c|c|c|}
\hline \multirow{2}{*}{$\begin{array}{c}\text { Name }\left(\begin{array}{l}1 \\
\text { b) }\end{array}\right) \\
\left(^{\circ}{ }^{\circ}\right)\end{array}$} & RA (J200) & \multirow{2}{*}{$\begin{array}{c}\operatorname{Dec}(\mathrm{J} 2000) \\
\left({ }^{\circ},{ }^{\prime}\right)\end{array}$} & \multirow{2}{*}{$\begin{array}{l}V_{\mathrm{c}}(6668) \\
\left(\mathrm{km} \mathrm{s}^{-1}\right) \\
\end{array}$} & \multirow[t]{2}{*}{ Ref. } \\
\hline & $\left(\begin{array}{lll}h & m & s\end{array}\right)$ & & & \\
\hline G33.980-00.019 & 185325.01 & 005525.98 & 59.0 & \\
\hline G34.096+00.018 & 185329.94 & 010239.40 & 56.1 & \\
\hline G34.195-00.593 & 185551.30 & 005113.58 & 61.7 & \\
\hline G34.244+00.133 & 185321.44 & 011344.40 & 54.9 & \\
\hline G34.284+00.184 & 185315.00 & 011712.99 & 51.8 & \\
\hline G34.396+00.222 & 185319.08 & 012413.80 & 55.7 & \\
\hline G34.411+00.235 & 185317.99 & 012525.26 & 63.1 & \\
\hline G34.751-00.093 & 185505.22 & 013436.26 & 52.9 & \\
\hline G34.757+00.025 & 185440.74 & 013806.40 & 76.5 & \\
\hline G34.791-01.387 & 185945.98 & 010119.00 & 46.9 & \\
\hline G34.822+00.352 & 185337.84 & 015033.00 & 59.6 & \\
\hline G35.132-00.744 & 185806.14 & 013707.50 & 35.4 & 2 \\
\hline G35.149+00.809 & 185235.96 & 022032.03 & 75.2 & \\
\hline G35.197-00.743 & 185813.05 & 014035.70 & 28.5 & 2 \\
\hline G35.200-01.736 & 190145.54 & 011332.60 & 44.5 & 1 \\
\hline G35.226-00.354 & 185653.15 & 015246.89 & 59.3 & \\
\hline G35.247-00.237 & 185630.38 & 015708.88 & 72.4 & \\
\hline G35.397+00.025 & 185550.78 & 021219.10 & 89.2 & \\
\hline G35.417-00.284 & 185659.02 & 020455.65 & 56.0 & \\
\hline G35.457-00.179 & 185640.98 & 020957.16 & 55.5 & \\
\hline G35.588+00.060 & 185604.22 & 022328.30 & 44.1 & \\
\hline G35.793-00.175 & 185716.89 & 022757.91 & 60.7 & \\
\hline G36.115+00.552 & 185516.79 & 030505.41 & 73.1 & \\
\hline G36.634-00.203 & 185855.23 & $03 \quad 1204.72$ & 77.3 & \\
\hline G36.705+00.096 & 185759.12 & 032406.11 & 53.0 & \\
\hline G36.839-00.022 & 185839.21 & 032800.90 & 61.6 & \\
\hline G36.918+00.483 & 185659.78 & 034603.60 & -35.8 & \\
\hline G37.030-00.039 & 185903.64 & 033745.09 & 80.2 & \\
\hline G37.043-00.035 & 185904.41 & 033832.80 & 80.2 & \\
\hline $\mathrm{G} 37.430+01.518$ & 185414.23 & 044141.10 & 41.2 & \\
\hline G37.479-00.105 & 190007.14 & 035953.35 & 54.7 & \\
\hline G37.546-00.112 & 190016.05 & 040316.09 & 49.9 & \\
\hline G37.554+00.201 & 185909.98 & 041215.54 & 83.6 & \\
\hline G37.598+00.425 & 185826.79 & 042045.46 & 87.0 & \\
\hline G37.735-00.112 & 190036.84 & 041320.00 & 50.3 & \\
\hline G37.753-00.189 & 190055.42 & 041212.56 & 54.6 & \\
\hline G37.767-00.214 & 190102.27 & 041216.60 & 69.0 & \\
\hline G38.038-00.300 & 190150.46 & 042418.96 & 58.1 & \\
\hline G38.119-00.229 & 190144.15 & 043037.42 & 70.4 & \\
\hline G38.203-00.067 & 190118.73 & 043934.29 & 84.2 & \\
\hline G38.255-00.200 & 190152.95 & 043839.47 & 73.1 & \\
\hline G38.258-00.073 & 190126.25 & 044219.90 & 15.4 & \\
\hline $\mathrm{G} 38.565+00.538$ & 185949.13 & 051528.90 & -28.8 & \\
\hline G38.598-00.212 & 190233.46 & 045636.40 & 62.5 & \\
\hline G38.653+00.088 & 190135.24 & 050747.36 & -31.5 & \\
\hline G38.916-00.353 & 190338.65 & 050942.49 & 31.9 & \\
\hline G39.100+00.491 & 190058.04 & 054243.90 & 15.9 & \\
\hline G39.388-00.141 & 190345.31 & 054042.68 & 60.2 & \\
\hline G40.282-00.219 & 190541.21 & 062612.69 & 73.9 & 2 \\
\hline G40.597-00.719 & 190803.29 & 062912.90 & 76.2 & \\
\hline G40.623-00.138 & 190601.63 & 064636.50 & 31.1 & 1 \\
\hline G41.075-00.125 & 190649.04 & 071106.57 & 57.5 & \\
\hline G41.121-00.107 & 190650.24 & 071401.49 & 36.6 & \\
\hline
\end{tabular}


Table A.2. continued.

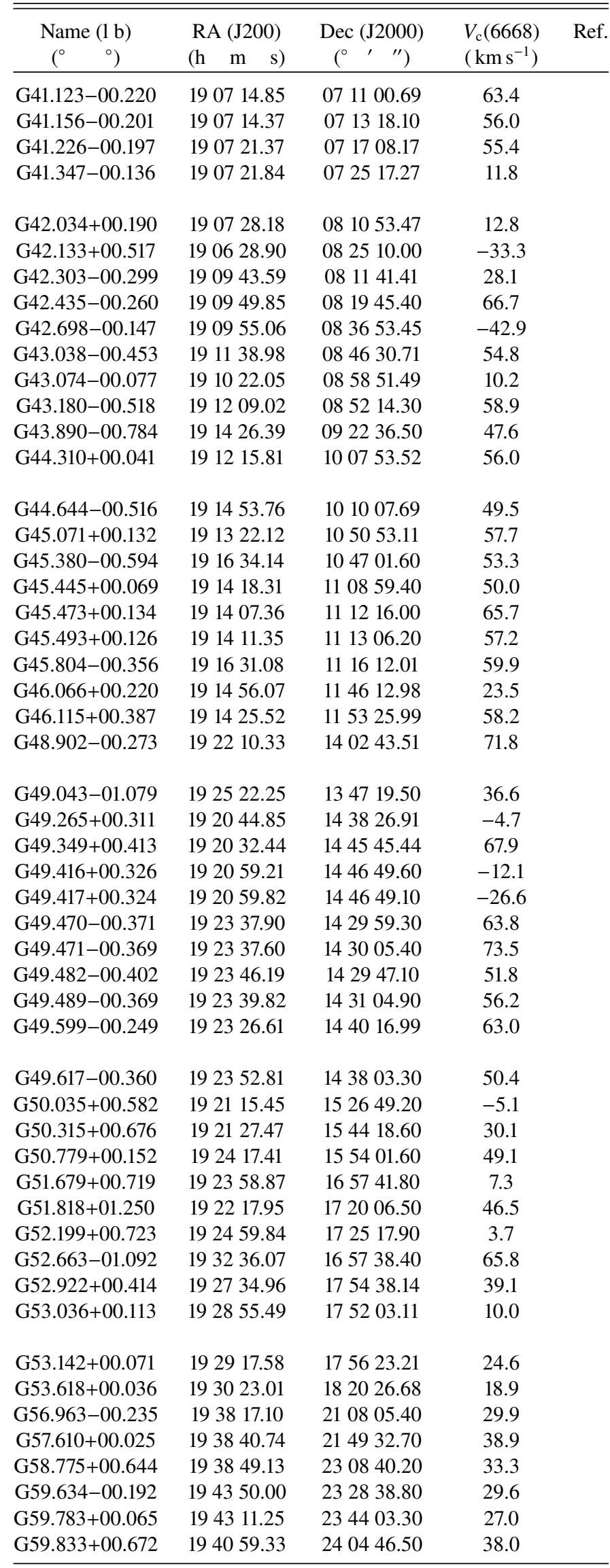

Table A.2. continued.

\begin{tabular}{|c|c|c|c|c|}
\hline \multirow{2}{*}{ Name (l b) } & RA (J200) & \multirow{2}{*}{$\begin{array}{c}\operatorname{Dec}(\mathrm{J} 2000) \\
\left({ }^{\circ}, \quad,\right)\end{array}$} & \multirow{2}{*}{$\begin{array}{l}V_{\mathrm{c}}(6668) \\
\left(\mathrm{km} \mathrm{s}^{-1}\right)\end{array}$} & \multirow[t]{2}{*}{ Ref } \\
\hline & $\left(\begin{array}{lll}h & \mathrm{~m} & \mathrm{~s}\end{array}\right)$ & & & \\
\hline G60.575+00.186 & 194552.48 & 241742.99 & 3.4 & \\
\hline G70.181+01.741 & 200054.16 & 333130.88 & -26.8 & \\
\hline G71.522+00.385 & 201257.91 & 333026.95 & 8.2 & \\
\hline G73.063+01.796 & 200810.20 & 355923.70 & 5.9 & \\
\hline G75.782+00.342 & 202144.05 & 372636.91 & -1.0 & \\
\hline G78.122+03.633 & 201426.04 & 411333.39 & -7.7 & \\
\hline G78.886+00.708 & 202924.94 & 401119.28 & -6.9 & \\
\hline G79.736+00.991 & 203050.67 & 410227.60 & -5.5 & \\
\hline G81.722+00.571 & 203901.05 & 422249.18 & -2.7 & 3 \\
\hline G81.744+00.590 & 203900.38 & 422436.91 & 4.0 & \\
\hline G81.752+00.590 & 203901.99 & 422459.08 & -5.7 & \\
\hline G81.871+00.780 & 203836.42 & 423734.56 & 6.3 & \\
\hline G94.602-01.796 & 213958.26 & 501420.96 & -40.8 & \\
\hline G97.521+03.172 & 213213.00 & 555256.00 & -71.2 & \\
\hline G107.288+05.638 & 222122.50 & 635113.00 & -8.5 & \\
\hline G108.184+05.519 & 222851.40 & 641341.31 & -11.0 & \\
\hline G108.766-00.986 & 225851.18 & 584514.37 & -46.3 & \\
\hline G109.871+02.114 & 225617.90 & 620149.65 & -3.7 & 3 \\
\hline G111.255-00.769 & 231610.33 & 595528.43 & -38.9 & \\
\hline G121.298+00.659 & 003647.35 & 632902.16 & -23.3 & \\
\hline G123.066-06.309 & 005224.19 & 563343.17 & -29.4 & \\
\hline G136.845+01.167 & 024933.59 & 604827.95 & -45.0 & \\
\hline G173.482+02.446 & 053913.05 & 354551.29 & -13.0 & \\
\hline G173.698+02.886 & 054137.40 & 354849.00 & -23.8 & \\
\hline G174.201-00.071 & 053048.01 & 334754.61 & 1.5 & \\
\hline G188.793+01.030 & 060906.96 & 215041.23 & -5.3 & \\
\hline G188.946+00.886 & 060853.34 & 213829.16 & 10.8 & \\
\hline G189.471-01.216 & 060208.37 & 200920.10 & 18.8 & \\
\hline $\mathrm{G} 189.777+00.344$ & 060835.30 & 203906.59 & 4.6 & \\
\hline G192.600-00.048 & 061254.02 & 175923.32 & 4.6 & \\
\hline G196.454-01.677 & 061437.05 & 134936.16 & 15.1 & \\
\hline G206.543-16.355 & 054144.15 & -015444.90 & 12.1 & \\
\hline G209.016-19.398 & 053513.95 & -052409.40 & -1.5 & \\
\hline G212.063-00.741 & 064712.90 & 002607.00 & 43.3 & \\
\hline G213.705-12.597 & 060747.86 & -062256.52 & 10.7 & \\
\hline G232.620+00.995 & 073209.78 & -165812.57 & 22.7 & \\
\hline
\end{tabular}


Table A.3. 6035 and $6031 \mathrm{MHz} \mathrm{OH}$ Zeeman pair candidates identified in the present sample.

\begin{tabular}{|c|c|c|c|c|c|c|c|c|}
\hline \multirow[b]{2}{*}{ Name } & \multicolumn{2}{|c|}{$\mathrm{LHC}$} & \multicolumn{2}{|c|}{$\mathrm{RHC}$} & \multirow[b]{2}{*}{$\begin{array}{c}V_{\mathrm{d}} \\
\left(\mathrm{km} \mathrm{s}^{-1}\right)\end{array}$} & \multirow[b]{2}{*}{$\begin{array}{c}B \\
(\mathrm{mG})\end{array}$} & \multirow[b]{2}{*}{ Reliability } & \multirow[b]{2}{*}{$\begin{array}{l}B_{\text {lit }} \\
(\mathrm{mG})\end{array}$} \\
\hline & $\begin{array}{c}V_{\mathrm{f}} \\
\left(\mathrm{km} \mathrm{s}^{-1}\right)\end{array}$ & $\begin{array}{c}S_{\mathrm{f}} \\
(\mathrm{Jy})\end{array}$ & $\begin{array}{c}V_{\mathrm{f}} \\
\left(\mathrm{km} \mathrm{s}^{-1}\right)\end{array}$ & $\begin{array}{c}S_{\mathrm{f}} \\
(\mathrm{Jy})\end{array}$ & & & & \\
\hline G11.034+00.062 & 23.93 & 1.83 & 23.71 & 0.92 & 23.82 & -3.9 & B & $-7.7^{(1)} ;-6.1^{(4)}$ \\
\hline G11.904-00.141 & 42.76 & 1.60 & 42.90 & 1.00 & 42.83 & +2.5 & A & $<0.5^{(1)} ;+1.6^{(4)}$ \\
\hline G12.209-00.102 & 16.96 & 1.77 & 17.34 & 2.00 & 17.15 & +6.8 & B & \\
\hline G12.681-00.182 & 59.72 & 1.93 & 60.39 & 1.57 & 60.06 & +12.0 & B & \\
\hline \multirow[t]{4}{*}{ G15.035-00.677 } & 21.43 & 38.29 & 21.46 & 29.11 & 21.45 & +0.6 & A & $<0.5^{(1)} ;+1.5^{(2)} ;+0.9^{(4)}$ \\
\hline & 22.63 & 19.55 & 22.63 & 21.63 & 22.63 & -0.1 & A & $-0.2^{(4)}$ \\
\hline & 23.60 & 7.53 & 23.36 & 3.88 & 23.48 & -4.2 & A & $-5.4^{(4)}$ \\
\hline & 21.53 & 6.40 & 21.54 & 2.85 & $21.54^{(a)}$ & +0.2 & A & $+0.5^{(4)}$ \\
\hline $\mathrm{G} 25.650+01.049$ & 39.53 & 2.81 & 39.25 & 1.77 & 39.34 & -5.4 & $\mathrm{~A}$ & \\
\hline \multirow[t]{2}{*}{ G28.201-00.049 } & 94.54 & 3.05 & 94.94 & 3.45 & 94.74 & +7.1 & $\mathrm{~B}$ & $+9.0^{(2)} ;+6.2^{(3)} ;+7.5^{(3)}$ \\
\hline & 94.47 & 0.75 & 95.02 & 1.31 & $94.74^{(a)}$ & +7.0 & B & \\
\hline $\mathrm{G} 35.025+00.350$ & 45.27 & 1.40 & 45.57 & 3.23 & 45.42 & +5.4 & B & $+5.0^{(1)}$ \\
\hline G43.149+00.013 & 11.15 & 3.22 & 10.84 & 3.03 & 11.00 & -5.5 & $\mathrm{~A}$ & $-4.3^{(2)}$ \\
\hline G43.796-00.127 & 40.18 & 0.56 & 40.44 & 0.59 & 40.31 & +4.6 & A & $+3.6^{(1)}$ \\
\hline \multirow[t]{5}{*}{ G45.467+00.053 } & 65.03 & 4.53 & 64.88 & 17.02 & 64.95 & -2.8 & A & $-3.2^{(3)}$ \\
\hline & 66.36 & 12.43 & 66.29 & 6.35 & 66.32 & -1.2 & A & \\
\hline & 67.71 & 4.11 & 68.05 & 3.31 & 67.88 & +6.0 & A & \\
\hline & 65.15 & 1.76 & 64.84 & 1.58 & $65.00^{(a)}$ & -3.9 & A & \\
\hline & 66.38 & 2.26 & 66.25 & 0.97 & $66.31^{(a)}$ & -1.6 & A & \\
\hline G48.990-00.299 & 67.52 & 1.74 & 67.64 & 3.91 & 67.58 & +2.1 & A & \\
\hline \multirow[t]{6}{*}{ G49.490-00.388 } & 52.26 & 1.72 & 52.55 & 1.75 & 52.40 & +5.0 & $\mathrm{~B}$ & $+5.0^{(2)},+3.9^{(3)}$ \\
\hline & 54.75 & 9.05 & 54.97 & 10.09 & 54.86 & +3.8 & $\mathrm{~B}$ & \\
\hline & 56.51 & 3.97 & 56.77 & 7.41 & 56.64 & +4.8 & A & \\
\hline & 57.65 & 2.21 & 57.94 & 1.99 & 57.79 & +5.3 & A & \\
\hline & 62.92 & 1.55 & 63.08 & 2.40 & 63.00 & +2.9 & A & \\
\hline & 52.30 & 4.70 & 52.67 & 2.92 & $52.48^{(a)}$ & +4.8 & A & \\
\hline \multirow[t]{3}{*}{ G69.540-00.976 } & 0.02 & 2.97 & -0.55 & 2.68 & -0.27 & -10.1 & B & $-2.7^{(3)}$ \\
\hline & 14.52 & 7.60 & 14.48 & 13.41 & 14.50 & -0.9 & B & \\
\hline & 14.09 & 1.77 & 13.79 & 2.62 & $13.94^{(a)}$ & -3.8 & $\mathrm{~A}$ & $-3.2^{(3)} ;-4.2^{(3)}$ \\
\hline \multirow[t]{3}{*}{ G80.861+00.383 } & -11.02 & 2.30 & -11.18 & 1.59 & -11.10 & -2.8 & A & $-4.3^{(3)}$ \\
\hline & -1.23 & 1.29 & -1.08 & 2.00 & -1.15 & +1.6 & A & \\
\hline & -11.02 & 1.34 & -11.25 & 1.52 & $-11.13^{(a)}$ & -2.9 & $\mathrm{~A}$ & $-3.2^{(3)} ;-2.7^{(3)}$ \\
\hline \multirow[t]{2}{*}{ G81.871+00.781 } & 7.44 & 8.63 & 7.85 & 13.96 & 7.65 & +7.4 & B & $+7.8^{(3)}$ \\
\hline & 8.67 & 4.97 & 9.13 & 1.47 & 8.90 & +8.3 & $\mathrm{~B}$ & $+7.5^{(3)}$ \\
\hline G85.410+00.003 & -32.90 & 0.66 & -32.97 & 1.98 & -32.93 & -1.2 & A & \\
\hline \multirow[t]{2}{*}{ G98.036+01.446 } & -62.77 & 0.58 & -62.58 & 0.58 & -62.68 & +3.4 & B & \\
\hline & -61.47 & 1.81 & -61.41 & 1.65 & -61.44 & +1.1 & A & \\
\hline \multirow[t]{2}{*}{ G108.766-00.986 } & -44.69 & 1.05 & -45.32 & 3.89 & -45.00 & -11.2 & $\mathrm{~B}$ & \\
\hline & -44.18 & 1.11 & -44.82 & 1.96 & -44.50 & -11.4 & $\mathrm{~B}$ & \\
\hline & -59.53 & 1.37 & -59.50 & 1.11 & -59.51 & +0.6 & B & \\
\hline \multirow[t]{3}{*}{ G133.947+01.064 } & -43.33 & 180.0 & -43.00 & 125.19 & -43.17 & +5.9 & $\mathrm{~B}$ & \\
\hline & -43.43 & 34.57 & -42.78 & 81.54 & $-43.10^{(a)}$ & +8.2 & B & \\
\hline & -42.82 & 19.97 & -42.11 & 20.25 & $-42.47^{(a)}$ & +9.0 & B & \\
\hline
\end{tabular}

Notes. The peak velocities $\left(V_{\mathrm{f}}\right)$ and peak flux densities $\left(S_{\mathrm{f}}\right)$ obtained by fitting Gaussian components to the spectra of LHC and RHC features are listed. The demagnetized velocities $\left(V_{\mathrm{d}}\right)$, magnetic field strength $(B)$ and estimates of the magnetic field strength from the literature $\left(B_{\mathrm{lit}}\right)$ are also given. The reliability parameter describes two cases of Zeeman splitting estimation: both polarised spectral features showed single Gaussian components (A) or were blended (B). ${ }^{(a)} 6031 \mathrm{MHz}$ transition.

References. ${ }^{(1)}$ Caswell \& Vaile (1995), ${ }^{(2)}$ Caswell (2003), ${ }^{(3)}$ Baudry et al. (1997), ${ }^{(4)}$ Green et al. (2015). 